\title{
LOS MERCADERES DE LA MUERTE EN COLOMBIA: MULTINACIONALES Y DERECHOS HUMANOS
}

\author{
THE MERCHANTS OF DEATH IN COLOMBIA: MULTINATIONALS AND \\ HUMAN RIGHTS
}

Por: Luis Alfonso Fajardo Sánchez PhD. ${ }^{1}$

Fecha de recepción: 25 de Julio de 2010

Fecha de aprobación: 22 de noviembre de 2010

\section{Resumen}

Durante casi ocho décadas varias regiones del país han sufrido graves violaciones a los derechos humanos e infracciones al DIH. Miles de campesinos, líderes sindicales y dirigentes políticos han sido asesinados, desaparecidos, desplazados, obligados a exiliarse, etc., pero ¿quiénes son los causantes de esas violaciones?, ¿en el actual mundo globalizado los actores del conflicto siguen siendo los mismos

\footnotetext{
${ }^{1}$ Doctor en Derecho, Programa de Derechos Fundamentales, Universidad Carlos III (Madrid, España); Doctor en Sociología y Ciencias Políticas de la Universidad Complutense de Madrid; Magíster en Teorías Críticas del Derecho, Universidad Internacional de Andalucía- España; Especialista en Derechos Humanos (ESAP); Diplomado de Derecho Internacional Humanitario, Instituto Internacional de Derecho Humanitario (San Remo, Italia); Diploma, Université d'eté des Droits de L'homme et du droit a l'education (Ginebra, Suiza); Diploma, Institut Internacional des Droits de L'homme (Strasbourg, Francia). Ha sido docente de las universidades Nacional, Javeriana, del Rosario y ESAP, y consultor de organizaciones nacionales e internacionales en temas de Derechos Humanos y Derecho Internacional Humanitario. En la actualidad es director de la Maestría en Derechos Humanos y DIH y de la Línea de Investigación “Derecho y Sociedad" en la Facultad de Derecho en la Universidad Santo Tomás. Ganador del premio al investigador del año 2009 otorgado por la Universidad Santo Tomás.
} 


\section{REVISTA VIRTUAL VIA INVENIENDI ET IUDICANDI \\ "CAMINO DEL HALLAZGO Y DEL JUICIO"}

http://viei.usta.edu.co/ E-MAIL: revistainveniendi@usantotomas.edu.co

de otros tiempos?, ¿el crimen ha evolucionado y avanzado a otras esferas?, ¿qué factores hacen que quienes cometen tales violaciones sean susceptibles de ser declarados responsables?

Los anteriores cuestionamientos tratan de abordarse en el presente artículo, el cual intenta hacer una lectura de la realidad colombiana, a partir de fuentes teóricas sobre los principios y funcionamiento de los mercados, especialmente, el actuar de algunas empresas multinacionales, en este caso: Chiquita Brands, Dole, Del Monte y Drummond, con presencia en Colombia, desde hace más de ochenta años, como es el caso de Chiquita Brands. Con ello, se trata de demostrar que estas empresas, según confesiones de los más altos jefes paramilitares de Colombia, no han tenido ningún reparo en pagar a estos grupos armados ilegales para aumentar su lucro y acabar con la voz de los trabajadores y de las comunidades y así ampliar de manera descomunal sus márgenes de ganancia.

En tal sentido, millones de colombianos pertenecientes a los grupos más vulnerables de la sociedad, mueren, desaparecen, son torturados, desplazados, exiliados, etc., como consecuencia de algunas acciones de las multinacionales instaladas en el país que no sólo aprovechan nuestros recursos y nuestra mano de obra a muy bajo precio, sino que financian a grupos ilegales para cometer las más graves violaciones de derechos humanos, con el objetivo de expandirse y aumentar sus ganancias. 


\section{REVISTA VIRTUAL VIA INVENIENDI ET IUDICANDI \\ "CAMINO DEL HALLAZGO Y DEL JUICIO"}

http://viei.usta.edu.co/ E-MAIL: revistainveniendi@usantotomas.edu.co

Intento mostrar la magnitud de las consecuencias humanitarias, sociales y políticas causadas por las multinacionales en nuestro territorio y otros posibles escenarios para ir en búsqueda de justicia ante tales vulneraciones. De esa forma, ante la falta de celeridad y eficacia de la justicia colombiana frente a las acciones de estas multinacionales en nuestro país, se hace referencia a otro mecanismo del que han tenido que usar las víctimas: los estrados estadounidenses fundamentados en la "Clausula Alien Tort Claim Act" - ATCA - responsabilidad extracontractual extranjera, en violación a la ley de las naciones, estatuto que prohíbe y castiga las graves violaciones de derechos humanos de nacionales estadounidenses en el extranjero o de extranjeros en el territorio estadounidense.

Este es el único camino que en el campo específico de las violaciones a los derechos humanos del que pueden hacer uso las víctimas de delitos causados por estas empresas en territorio colombiano, ya que Estados Unidos se ha caracterizado por ser un país reservado en cuanto a la ratificación de diversos instrumentos de derechos humanos y derecho internacional humanitario, como el Estatuto de Roma.

Sin embargo, a falta de normatividad interna con relación a violaciones de derechos humanos como ya se mencionó, diversas decisiones judiciales se han basado en la Ley de Responsabilidad por Daños a Extranjeros (Alien Tort Claims Act o Alien Tort Statute-ATCA). 


\section{REVISTA VIRTUAL VIA INVENIENDI ET IUDICANDI \\ "CAMINO DEL HALLAZGO Y DEL JUICIO"}

http://viei.usta.edu.co/ E-MAIL: revistainveniendi@usantotomas.edu.co

En ese contexto, adquiere relevancia el análisis de esta norma, que se ha constituido como un elemento importante para establecer la responsabilidad de las empresas multinacionales por implicación en graves violaciones de derechos humanos. La aplicación del ATCA pone de manifiesto una clara conciencia de que las empresas multinacionales pueden considerarse entre los sujetos susceptibles de violar el derecho internacional y que como tales pueden enfrentarse a procesos para determinar su responsabilidad. En ese sentido, puede decirse que esta jurisprudencia ha contribuido a la consideración de que el derecho internacional impone la obligación a estas empresas de no violar normas de lus Cogens y que dicha violación pueda tener una consecuencia jurídica.

\section{Palabras clave}

Globalización, derechos humanos, multinacionales, crímenes de lesa humanidad, Ley de Responsabilidad por Daños a Extranjeros, (Alien Tort Claims Act o Alien Tort Statute-ATCA).

\section{Abstract}

For over fifteen years, several regions have suffered serious human rights violations and breaches of IHL. Thousands of peasants, union leaders and political leaders have been killed, disappeared, displaced, forced into exile, and so on, but who are the perpetrators of such violations? On today's globalized world the conflict actors remain the same for other times?, Does the crime has evolved and 


\section{REVISTA VIRTUAL VIA INVENIENDI ET IUDICANDI \\ "CAMINO DEL HALLAZGO Y DEL JUICIO"}

http://viei.usta.edu.co/ E-MAIL: revistainveniendi@usantotomas.edu.co

progressed to other areas?, What factors make people who commit such violations are likely to be held responsible?

All of the above questions, try to be addressed in this article where it's being from theoretical sources on the principles and functioning of markets be closer to the Colombian reality, especially multinational corporations act Chiquita Brands, Dole, Del Monte and Drummond, from operating in Colombia, more than eighty years, in the case of Chiquita Brands. This is to prove that these companies, as higher denominations of paramilitary leaders in Colombia have had no qualms about paying these illegal armed groups to end just with the participation of workers and communities in decisions their environment.

In this regard million Colombians, belonging to the most vulnerable groups of Colombian society, die, disappear, are tortured, displaced, exiled, etc. As a result of the actions of multinationals established in our country that not only leverage our resources and our workforce at a very low price, but that fund illegal groups to commit the most serious human rights violations, in order to expand and increase profits.

We try to show the magnitude of the negative consequences caused by the multinationals in our territory and the other possible scenarios to go in search of justice against such violations. Thus, the lack of speed and efficiency of the 


\section{REVISTA VIRTUAL VIA INVENIENDI ET IUDICANDI \\ "CAMINO DEL HALLAZGO Y DEL JUICIO"}

http://viei.usta.edu.co/ E-MAIL: revistainveniendi@usantotomas.edu.co

Colombian justice against the actions of such multinationals in our territory, refers to another mechanism we have had to use the victims of these companies: American podium with basis for the "ALIEN TORT CLAIM ACT CLAUSE - ATCA foreign torts in violation of the law of nations, statute that prohibits and punishes the serious human rights violations of United States nationals abroad or foreigners in the U.S. territory.

This is the only way that specific field of human rights violations victims can make use of events caused by these companies in Colombia, as the United States has been characterized as a country reserved the ratification of various human rights instruments and international humanitarian law, as the Rome Statute.

However, lack of internal regulations regarding human rights violations as mentioned above, various court decisions have been based on the Act on Liability for Damage to Aliens (Alien Tort Claims Act or ATCA, Alien Tort Statute)

In this context, the analysis becomes relevant to this rule, which has established itself as an important element to establish the liability of multinational corporations for involvement in human rights violation. The application of the ATCA shows a clear awareness that multinational companies can be among the subjects might violate international law and as such may face proceedings to determine responsibility. In that sense, it can be said that this case has contributed to the 


\section{REVISTA VIRTUAL VIA INVENIENDI ET IUDICANDI \\ "CAMINO DEL HALLAZGO Y DEL JUICIO"}

http://viei.usta.edu.co/ E-MAIL: revistainveniendi@usantotomas.edu.co

view that international law imposes an obligation on these companies not to violate norms of Jus Cogens and that this violation may have a legal consequence .

\section{Key Words}

Globalization, human rights, multinational, crimes against humanity, Alien Tort Claims Act o Alien Tort Statute-ATCA

\section{PRESENTACIÓN}

El presente capítulo intenta acércanos a la realidad colombiana, especialmente al funcionamiento de las empresas multinacionales Chiquita Brands, Dole, Del Monte y Drummond, entre otras, en Colombia, a partir de fuentes teóricas sobre los principios y funcionamiento de los mercados y del documental La Corporación.

La hipótesis es demostrar que estas empresas no sólo carecen de ética en sus pretensiones de lucro y ganancia desmedida, desconocen que existen valores, principios y derechos que no pueden ser susceptibles de compra y venta, sino que además han sido denunciadas e incluso condenadas, en el caso de Chiquita Brands, de financiar grupos armados ilegales para cometer las más graves violaciones a los derechos humanos que han tenido lugar en el país.

Estas empresas, que han operado en total impunidad hasta hoy, son el más claro ejemplo del desconocimiento de cualquiera de las llamadas por el profesor 


\section{REVISTA VIRTUAL VIA INVENIENDI ET IUDICANDI \\ "CAMINO DEL HALLAZGO Y DEL JUICIO"}

http://viei.usta.edu.co/ E-MAIL: revistainveniendi@usantotomas.edu.co

Ernesto Garzón Valdés, "justificaciones deontológicas del mercado", en las que se parte del supuesto: "el mercado es el resultado del ejercicio de derechos básicos de la persona”².

Una de las premisas es que el mercado es un elemento dinamizador de la democracia, pero que no se cumple en el caso de estas empresas, porque no han tenido ningún reparo en pagar a grupos paramilitares, para acabar con la participación de los trabajadores y de las comunidades en las decisiones de su entorno, en este sentido, estas empresas son sinónimo de anti-democracia.

\section{EL MERCADO: UN JUEGO SIN REGLAS}

Luego de un estudio detallado de la relación entre mercado y justicia, concluye el profesor Ernesto Garzón Valdés, que no todos los bienes son susceptibles de comercio ni deben estar incluidos en el mercado. Para defender esta idea sostiene que es necesario respetar un "coto vedado", es decir, el conjunto de derechos vinculados con la satisfacción de las necesidades básicas, los cuales por ser un prerrequisito de la democracia representativa, no pueden ser objeto de la negociación y el compromiso. Este concepto lo construye retomando las tesis de Amartya Sen. En este "coto vedado" se encuentran todos los valores, principios

\footnotetext{
${ }^{2}$ Ernesto Garzón Valdés. Los textos que se reúnen bajo este título fueron presentados en el II S e m i n a ri o Eduardo García Máynez sobre Teoría y Filosofía del Derecho, organizado por el Instituto Tecnológico Autónomo de México (ITAM) y la Escuela Libre de Derecho. El evento se llevó a cabo en la Ciudad de México los días 15, 16 y 17 de octubre de 1992, p. 7.
} 


\section{REVISTA VIRTUAL VIA INVENIENDI ET IUDICANDI \\ "CAMINO DEL HALLAZGO Y DEL JUICIO"}

http://viei.usta.edu.co/ E-MAIL: revistainveniendi@usantotomas.edu.co

y derechos que las personas necesitan para desarrollar sus proyectos de vida en las condiciones máximas de dignidad.

Concluye Garzón Valdés:

"La cuestión no es de todo o nada sino del hasta dónde. Dicho con otras palabras: qué es lo que puede ser objeto de transacción en el mercado. Mi respuesta es que al mercado pueden llevarse todos los bienes que no estén incluidos en el coto vedado (...) llego ahora a una conclusión final si se quiere trivial: porque el mercado es el ámbito de la negociación y el compromiso es obvio que sólo vale para lo que es negociable y acordable. $Y$ lo negociable y acordable no puede ser decidido en el mercado sino que requiere la aceptación de un sistema normativo superior. Este es el de la justicia como virtud social. Sólo desde él pueden formularse los arreglos institucionales que confieren calidad moral al instrumento del mercado. Quien pretenda invertir el razonamiento e inferir valores morales de la actividad incontrolada del mercado habrá de perder su cabeza bajo la guillotina de Hume"3.

Las reglas que insistentemente se han enunciado por los teóricos del mercado no las cumplen las grandes corporaciones y empresas multinacionales para

\footnotetext{
${ }^{3}$ Garzón Valdés, Ernesto. Los textos que se reúnen bajo este título fueron presentados en el II S e $\mathrm{m}$ i $\mathrm{n}$ a $\mathrm{r}$ i o Eduardo García Máynez sobre Teoría y Filosofía del Derecho, organizado por el Instituto Tecnológico Autónomo de México (ITAM) y la Escuela Libre de Derecho. El evento se llevó a cabo en la Ciudad de México los días 15, 16 y 17 de octubre de 1992.
} 


\section{REVISTA VIRTUAL VIA INVENIENDI ET IUDICANDI \\ "CAMINO DEL HALLAZGO Y DEL JUICIO"}

http://viei.usta.edu.co/ E-MAIL: revistainveniendi@usantotomas.edu.co

quienes el mercado es un juego sin reglas. No hay reglas que ellos estén dispuestos a cumplir, aunque sí son implacables para que sus reglas se impongan en todas partes del mundo "en el mercado todo vale"

A pesar de la insistencia de investigadores como Pedro Francés Gómez, docente de la Universidad Complutense de Madrid, de querer demostrar que el mercado sí tiene una reglas y que quienes deciden jugar deben estar dispuestos a cumplirlas; incluso en los planteamientos más liberales, como los de F. Von Hayek, celosas de cualquier reglamentación o normatividad, las empresas multinacionales no sólo no obedecen ninguna reglamentación u norma, sino que combaten y destruyen aquellas que les fijan alguna restricción a su voracidad.

Las empresas multinacionales han conseguido imponer su propio sistema legal para facilitar sus operaciones desde esta posición de dominio absoluto, las corporaciones se han lanzado al proyecto no sólo de controlar el poder y el dinero, sino las mentes de las personas, a través de una publicidad que ya no vende productos, sino estilos de vida, y que se reproduce en todos los rincones de nuestra existencia; pretenden ocupar nuestro espacio mental hasta el punto de que ya no tengamos capacidad de decisión autónoma.

Más de la tercera parte de las transnacionales son estadounidenses, Las cuales surgieron con las inversiones directas de Estados Unidos en Europa en los años 


\section{REVISTA VIRTUAL VIA INVENIENDI ET IUDICANDI \\ "CAMINO DEL HALLAZGO Y DEL JUICIO"}

http://viei.usta.edu.co/ E-MAIL: revistainveniendi@usantotomas.edu.co

cincuenta y sesenta del siglo XX. Este fenómeno se hizo mundial cuando se sumaron a él las empresas europeas y japonesas. Estas multinacionales actualmente tienen presencia en todos los continentes, influyendo en su economía, en las comunicaciones, en su cultura y en los demás aspectos de la vida de todos sus habitantes.

El carácter imperial, no «global», de la expansión de los capitales multinacionales y la primacía de las multinacionales estadounidenses en la «nueva» economía se torna evidente en la información publicada por el Financial Times (1999). Un examen de las 500 corporaciones líderes demuestra la ascendencia del poder imperial estadounidense. Entre las primeras 500 corporaciones, 244 o el $48 \%$ son propiedad estadounidense; 173 , el $35 \%$ son europeas; y 58, el $23 \%$ asiáticas (de las cuales 46 son japonesas). Es absurdo hablar de "globalización" cuando los propietarios y directores de la mayoría de las corporaciones y bancos que controlan el flujo internacional del capital son estadounidenses. En estas circunstancias, la "globalización" constituye una ideología que encubre la verdadera estructura del poder y la dominación. “América ya no es un país, es una marca de muchos trillones de dólares. América ${ }^{\circledR}$ no se diferencia prácticamente en nada de McDonald's, Marlboro o General Motors. Es una imagen que se les "vende" no sólo a los ciudadanos de Estado Unidos sino a los consumidores de

todo el mundo. La marca americana está asociada a eslóganes como la "democracia", "oportunidad" y "libertad" 


\section{REVISTA VIRTUAL VIA INVENIENDI ET IUDICANDI \\ "CAMINO DEL HALLAZGO Y DEL JUICIO"}

http://viei.usta.edu.co/ E-MAIL: revistainveniendi@usantotomas.edu.co

Según Kalle Lansn: América® ha sido socavada por los planes empresariales. Sus representantes electos se arrodillan ante el poder empresarial como condición para sobrevivir en el cargo. Se ha instaurado un sentimiento colectivo de importancia y desilusión. La cultura americana ya no es algo creado por la gente, nuestras historias que eran transmitidas por padres, vecinos y maestros de generación en generación, son ahora contadas por empresas distantes que tienen "algo que vender, además de algo que decir". Nuestro papel se reduce básicamente a escuchar y mirar - y después, según lo que hemos oído y hemos visto, a comprar. En la América ${ }^{\circledR}$ actual ya no es posible llevar una vida libre y auténtica. Un continuo mensaje comercial se ha incrustado en el tejido mismo de nuestra existencia. Nosotros mismos hemos sido convertidos en marca (1999, pp. 23-30).

El propósito económico que inspiró la globalización es, sin lugar a duda, el crecimiento económico de la clase empresarial, pero no hay evidencia de que la cuestión del desarrollo del ser humano sea importante en el movimiento, ahora precipitadamente a flote en todas partes del mundo. Como tal, la globalización puede ser una buena estrategia para la acumulación de riquezas, pero esas riquezas son ante todo para unos pocos y no integra ninguna política proyectada para el desarrollo de una comunidad o una población (Lans, 1999, pp. 23-30). 


\section{REVISTA VIRTUAL VIA INVENIENDI ET IUDICANDI \\ "CAMINO DEL HALLAZGO Y DEL JUICIO"}

http://viei.usta.edu.co/ E-MAIL: revistainveniendi@usantotomas.edu.co

Ahora bien, es importante señalar que la globalización surge a la par con el neoliberalismo, pues tal sistema es la principal herramienta con la cual tiene el acceso a los países. En ese sentido, su génesis proviene de la desaparición del mundo bipolar (Estados Unidos versus la Unión de Repúblicas Socialistas Soviéticas) y la búsqueda de relacionarse mediante la diplomacia comercial. El paradigma verdadero que evidencia este contexto histórico es, sin duda, la caída del muro de Berlín en el año de 1989.

La globalización surge de la necesidad que existe de interactuar con otros países, gracias al aumento masivo de la tecnología, visto en la tecnificación de las comunicaciones, así como en la propuesta de comerciar libremente en los mercados, apoyados en ese ente económico llamado neoliberalismo, sin embargo, ello trae consigo intereses más destinados a beneficios particulares que al mejoramiento de la calidad de vida de la mayoría, es decir, del colectivo.

Tiene su contrapartida en la formación transnacional de clases y en la emergencia de un estado transnacional que ha venido a existir para funcionar como la autoridad colectiva para la clase global gobernante. (...) en la actualidad, la globalización del proceso de producción está unificando al mundo en un solo modo de producción y en un solo sistema global, y está llevando a cabo la integración orgánica de diferentes países y regiones en la economía global (...). Se registra una subordinación de la 


\section{REVISTA VIRTUAL VIA INVENIENDI ET IUDICANDI \\ "CAMINO DEL HALLAZGO Y DEL JUICIO"}

http://viei.usta.edu.co/ E-MAIL: revistainveniendi@usantotomas.edu.co

lógica de la geografía a la lógica de la producción y este proceso que no tiene precedentes históricos, (...) nos obliga a reconsiderar la geografía y las políticas del estado-nación (Robinson, 2000).

En tal sentido, parece que uno de los enfoques, aún vigentes, sigue siendo el de Pierre Bourdiue, quien cuestionaba los principios ideológicos sobre los cuales se defendía el neoliberalismo, ocultando los verdaderos intereses de un muy pequeño grupo de personas en el mundo, interesadas en explotar a la gran mayoría. Su ensayo sobre "la esencia del liberalismo" desnuda lo que muchos teóricos de los mercados quieren ocultar con sus fórmulas y sugestivas propuestas; el neoliberalismo encarnado, entre otras, por las empresas multinacionales.

Dice Bourdieu que el neoliberalismo no es más que el darwinismo social, llevado a extremos injustificados, la precariedad laboral, la flexibilización, la ausencia de una seguridad laboral, la explotación, en fin, la VIOLENCIA ESTRUCTURAL. Todo esto no puede sino augurar un futuro de muerte (Bourdieu, 1998). 


\section{LA LÓGICA DE LAS MULTINACIONALES. UN LOCALISMO GLOBALIZADO}

Dice Juan Carlos Tudesco: "Al estar basada fundamentalmente en la lógica económica y en la expansión del mercado, la globalización rompe los compromisos locales y las formas habituales de solidaridad y de cohesión con nuestros semejantes. Las élites que actúan a nivel global tienden a comportarse sin compromisos con los destinos de las personas afectadas por las consecuencias de la globalización. La respuesta a este comportamiento por parte de los que quedan excluidos de la globalización es el refugio en la identidad local en la que la cohesión del grupo se apoya en el rechazo a los 'externos' (Tedesco, 2000).

Este peligro ya ha mostrado sus consecuencias en el mundo. La crisis asiática fue uno de los acontecimientos más grandes que puso en evidencia los peligros de la globalización: en algunos países asiáticos que presentaron gran crecimiento temporal, las inversiones disponibles después de un tiempo dejaron de ser tan rentables, produciéndose una desaceleración de la economía que desincentivó la inversión, generándose fugas de grandes recursos hacia otros destinos, con graves consecuencias para los socios comerciales de estos países. Por ejemplo, el sector financiero japonés tenía invertido aproximadamente el $40 \%$ de su cartera en el sudeste asiático; al sobrevenir la crisis, la quiebra de corporaciones e 


\section{REVISTA VIRTUAL VIA INVENIENDI ET IUDICANDI \\ "CAMINO DEL HALLAZGO Y DEL JUICIO"}

http://viei.usta.edu.co/ E-MAIL: revistainveniendi@usantotomas.edu.co

instituciones fue masiva, con terribles efectos para los habitantes de estos países y los de otros en los cuales estos bancos hacían presencia, incluyendo el propio Japón (CEPAL - ONU, 2002).

Como ya se ha demostrado con incontables estudios, el proceso de globalización no es únicamente económico, es cultural, ambiental, entre otros, también se ha desarrollado con aspectos positivos y negativos; sin embargo, siendo éste un sistema cada vez más predominante, es necesario que se encamine hacia la búsqueda del bienestar humano, hacia la búsqueda de soluciones a los problemas y necesidades sociales y económicas de las naciones y del mundo en general. (CEPAL - ONU, 2002)

Boaventura de Souza Santos, ilustre profesor de la Universidad de Coimbra, define globalización como "un proceso a través del cual una determinada condición o entidad local amplía su ámbito a todo el globo y, al hacerlo, adquiere la capacidad de designar como locales las condiciones o entidades rivales" (De Sousa Santos, 1998, p. 288).

Sobre esta globalización desmedida, que destruye la naturaleza del hombre, transformándolo en un consumidor en potencia, el libro Sabotaje Cultural. Manual de uso del activista Kalle Lasn, señala: 


\section{REVISTA VIRTUAL VIA INVENIENDI ET IUDICANDI \\ "CAMINO DEL HALLAZGO Y DEL JUICIO"}

http://viei.usta.edu.co/ E-MAIL: revistainveniendi@usantotomas.edu.co

Estados Unidos ya no es un país, sino una marca. Las empresas multinacionales han conseguido imponerse en un sistema legal que ya sólo existe para facilitar sus operaciones. Desde esta posición de dominio absoluto, las corporaciones se han lanzado al proyecto no sólo de controlar el poder y el dinero, sino las mentes de todos.

A través de una publicidad que ya no vende productos, sino estilos de vida, y que se reproduce en todos los rincones de nuestra existencia, las multinacionales pretenden ocupar nuestro espacio mental hasta el punto de que ya no tengamos capacidad de decisión autónoma.

De la misma forma que se lucha para salvar el planeta de la contaminación ambiental, se debe iniciar una cruzada para denunciar la contaminación de nuestro espacio mental, utilizando el sabotaje cultural, la contra publicidad y la manipulación de memes (Lans, 1999, p. 237).

\section{LA CORPORACIÓN: ¿QUE ES REALMENTE?}

El documental canadiense La Corporación, realizado por Mark Achbar, Jennifer Abbott y Joel Bakan muestra la cruda realidad de las corporaciones, que se han venido convirtiendo en la institución predominante del mundo globalizado, a las cuales se les atribuye la calidad de personas, con lo que surge la pregunta sobre 


\section{REVISTA VIRTUAL VIA INVENIENDI ET IUDICANDI \\ "CAMINO DEL HALLAZGO Y DEL JUICIO"}

http://viei.usta.edu.co/ E-MAIL: revistainveniendi@usantotomas.edu.co

qué tipo de personas son y descubriendo así que la mayoría de sus cualidades se adaptan a las características de la personalidad psicópata ${ }^{4}$.

En el documental se exponen los diferentes puntos de vista de profesores, científicos, investigadores, empresarios, presidentes de importantes corporaciones, entre otras, concluyendo que las personas están domesticadas o prontas a ser domesticadas por el poderío de las corporaciones en la sociedad global.

El poderío de las corporaciones ha sido parte de una evolución histórica, "el papel del dominio de las corporaciones viene del siglo pasado, en su origen las corporaciones eran asociaciones de personas constituidas legalmente por un Estado para realizar una determinada función" (Anderson en Achbar, Bakan \& Abbott, 2003).

Es el Estado el que ha permitido el crecimiento de esta figura, en primer lugar, al atribuirle calidad de persona jurídica, lo que conlleva un sinnúmero de derechos, con pocos límites y regulaciones, sin tener en cuenta que el espíritu creador de

\footnotetext{
${ }^{4}$ Una de las preguntas que surge es: ¿̇hasta qué punto una compañía puede considerarse psicópata, si la compañía es una persona jurídica?, no puede ser tan difícil definir la transición entre la psicopatía de un individuo y la de una corporación, analizando una a una las características de este trastorno para ver cómo aplican a la corporación.

Diagnóstico 1: Indiferencia al sentimiento de los demás. Diagnóstico 2: Incapacidad para mantener relaciones duraderas. Diagnóstico 3: Inferencia imprudente por la seguridad de otros. Diagnóstico 4: Engaño, mentir para beneficiarse. Diagnóstico 5: Incapacidad por sentir culpa. Diagnóstico 6: No acata normas sociales ni respeta conducta legal.
} 


\section{REVISTA VIRTUAL VIA INVENIENDI ET IUDICANDI \\ "CAMINO DEL HALLAZGO Y DEL JUICIO"}

http://viei.usta.edu.co/ E-MAIL: revistainveniendi@usantotomas.edu.co

estas instituciones era otro totalmente diferente al manejado actualmente, "a nivel social la corporación se consideraba como una propiedad subordinada, como un regalo para la gente" (Gnoss Man, 2003).

La problemática generada con la atribución de la calidad de ser persona, se dio a raíz de que:

Se creó la llamada décima cuarta enmienda, la cual estaba destinada para garantizar los derechos de los esclavos, aprobada después de la guerra civil, esta garantizaba los mismos derechos para las personas blancas como para las personas negras. Pero los abogados de las corporaciones señalaban que "no se puede privar a una persona de su vida y su libertad, ¡pues nosotros somos una persona, el tribunal supremo lo admitía. (Zinn, 2003, La Corporación).

Lo difícil de esta realidad, es que el espíritu de la decimocuarta enmienda fue el de "proteger a los esclavos, recién liberados [pero] Entre 1890 y 1910 se realizaron 307 juicios relacionados con la décimo cuarta enmienda, de los cuales 288 fueron establecidos por corporaciones y sólo 19 por personas afroamericanas" (Chomsky, 2003, La Corporación).

Lo anterior demuestra que la atribución de la calidad de persona a las corporaciones, les suministró un plexo de derechos que a su vez dieron lugar al 


\section{REVISTA VIRTUAL VIA INVENIENDI ET IUDICANDI \\ "CAMINO DEL HALLAZGO Y DEL JUICIO"}

http://viei.usta.edu.co/ E-MAIL: revistainveniendi@usantotomas.edu.co

crecimiento de esta institución en la historia y en la sociedad, extendiendo su emporio más allá de los territorios de donde surgieron.

Los principios operativos de la empresa le dan una muy anti-social "personalidad", en la cual la artista principal es el egoísmo, la búsqueda de interés propio, una moral cruel y engañosa que en muchos casos se disfraza de preocupación social y sentimientos de altruismo. Cuatro estudios de casos tomados de un universo de la actividad empresarial, demuestran claramente el daño a los trabajadores a la salud humana, a los animales y al medio ambiente.

Las corporaciones, que cotizan en el mercado tienen una estructura, estipulada por la ley, con características determinadas, la ley las obliga a poner sus intereses financieros, los de sus propietarios por encima de otros intereses, de hecho por ley la corporación está obligada a poner sus resultados por encima de todo lo demás, inclusive hasta por encima del bien público (Achbar, Bakan \& Abbott, 2003).

¿Hasta qué punto podemos tomar la corporación como una persona, puede que podamos comparar la sicopatía de la corporación como persona, al ser analizada la corporación tiene el perfil diagnosticable de un psicópata, si ésta ha sido creada a imagen y semejanza del psicópata 


\section{REVISTA VIRTUAL VIA INVENIENDI ET IUDICANDI \\ "CAMINO DEL HALLAZGO Y DEL JUICIO"}

http://viei.usta.edu.co/ E-MAIL: revistainveniendi@usantotomas.edu.co

quién tendrá el dominio de sus actos? (Hare en Achbar, Bakan \& Abbott, 2003).

El interrogante que surge es ¿qué clase de personas conforman este cúmulo de poder?, “¿por qué La corporación no es una persona? La gente que trabaja para ella piensa, y para ellos es fruto producir tecnología suicida. Está claro, que los beneficios son sólo para ellos, es la realidad (Chiva en Achbar, Bakan \& Abbott, 2003). No se puede olvidar que quienes conforman estas instituciones son seres humanos, que al igual que la organización de la que son parte, buscan productividad económica, olvidándose de los principios que como seres humanos, deberían tener.

Incluso, los desastres pueden ser vistos como oportunidades, para estos grupos, Carlton Brown, un corredor de bolsa, cuenta con honestidad valiente la mentalidad de los comerciantes de oro, mientras que las torres gemelas aplastó a sus ocupantes. Lo primero que vino a sus mentes, nos dice, fue: "¿Cuánto costará el oro?"

La guerra, que ha producido tantas nefastas consecuencias en el mundo entero, también puede ser vista como una catástrofe beneficiosa para las empresas:

La guerra es buena porque es mucho mayor la venta, materias primas, las catástrofes traen oportunidades. Cuando Estados Unidos bombardeo a 


\section{REVISTA VIRTUAL VIA INVENIENDI ET IUDICANDI \\ "CAMINO DEL HALLAZGO Y DEL JUICIO"}

http://viei.usta.edu.co/ E-MAIL: revistainveniendi@usantotomas.edu.co

Irak, todos estábamos dichosos eso hazlo porque así podremos subir el precio del petróleo, la gente hablaba de 60 u 80 euros. Estábamos entusiasmados aunque fuera una catástrofe (Brown, Achbar, Bakan \& Abbott, 2003).

La libertad de actuación de las corporaciones es el mayor error que tiene la sociedad, pues el no crear un límite legal o moral, es lo que permite que cada vez adquieran más poder, pues se encuentran en total libertad en el mundo entero, de buscar sus beneficios a costa de cualquier cosa, "Sí, realmente había una mano libre, se trataba realmente de lo que se quería hacer, de adaptar las ideas y las prioridades, no se podía actuar de otra manera (Gibara en Achbar, Bakan \& Abbott, 2003).

De igual forma, hay otros personajes, en el video mencionado, que presentan preocupación por el daño que producen las corporaciones de las que son parte, producen, como el caso de Sir Mark Moody-Stuart quien narra un intercambio entre él (en el momento Presidente de la Royal Dutch Shell), y su esposa con un variado equipo de activistas de Earth First, quienes llegaron a las puertas de su hogar, cantando y extendieron una bandera desde su techo que decía: "ASESINOS". La pareja sorprendió a los jóvenes, cuando en vez de llamar a la policía, los invitó a participar a un diálogo y compartir sus preocupaciones acerca 


\section{REVISTA VIRTUAL VIA INVENIENDI ET IUDICANDI \\ "CAMINO DEL HALLAZGO Y DEL JUICIO"}

http://viei.usta.edu.co/ E-MAIL: revistainveniendi@usantotomas.edu.co

de los derechos humanos y el medio ambiente, para finalmente, servir té en su césped.

Estoy escuchando sus dudas, porque me preocupa el medio ambiente, me preocupa mi nación, yo no tengo todas las respuestas, pero estoy trabajando en ello, preparado para trabajar con vosotros con la sociedad, las ONG, y con los gobiernos para conseguir la confianza y el objetivo es ser la corporación favorita (Achbar, Bakan \& Abbott, 2003).

Sin embargo, la Shell es una de las principales corporaciones que atenta contra el medio ambiente.

Ray Anderson, presidente de la Interfaz Inc, el fabricante de alfombras comerciales más grande del mundo, aceptó la responsabilidad de muchas de las violaciones en la que ha incurrido, y comentó el momento en el cual inició su cambio:

Una vez los clientes empezaron a preguntar ¿qué estaba haciendo por el medio ambiente?, la verdadera respuesta era no mucho. Entonces me puse en la tarea de buscar información acerca de esto, ya que no tenía ni la menor idea, y encontré un libro, en donde la primera expresión fue "la muerte del nacimiento" expresión de Deo Wilson, a propósito de la extinción de las especies, fue como si se me clavara una lanza en el pecho, fue un cambio de paradigma. Algunos productos no deberían 


\section{REVISTA VIRTUAL VIA INVENIENDI ET IUDICANDI \\ "CAMINO DEL HALLAZGO Y DEL JUICIO"}

http://viei.usta.edu.co/ E-MAIL: revistainveniendi@usantotomas.edu.co

hacerse de ninguna forma, no creo igual que tengamos gente que haga productos y al mismo tiempo haga productos insostenibles. La forma en que había manejado Interface era saqueando cosas que no me pertenecían, pertenecen a todas las criaturas de la tierra y se me decía "Dios mío debe llegar el día en que no existan más saqueos, debe llegar el día, llegará el día en que termine en la cárcel".

Anderson ha observado con preocupación los efectos en el medio ambiente, a costa de la productividad de su empresa, por lo que la ha re-organizado e invertido US\$1.4 mil millones en los principios de sostenibilidad ambiental. Su empresa puede ser un faro de esperanza de las empresas, pero lastimosamente, es una excepción a la regla.

Lo más preocupante es que ya ningún objeto es "sagrado" para las corporaciones, en su afán de lucro, explotan ilimitadamente, bienes tan primordiales para la existencia humana como el agua, alimentos, animales, niños, niñas, entre tantas otras cosas. Ya no se tiene límite de qué es objeto de comercio, y qué no, de un comercio con reglas establecidas y respeto a ellas, si no bienes de los que se busca el único provecho de ganancia económica. Hoy en día, cada molécula en el planeta está en juego. En un intento de poseer todo, las empresas quieren tener las patentes de animales, plantas, e incluso su ADN. 


\section{REVISTA VIRTUAL VIA INVENIENDI ET IUDICANDI \\ "CAMINO DEL HALLAZGO Y DEL JUICIO"}

http://viei.usta.edu.co/ E-MAIL: revistainveniendi@usantotomas.edu.co

Hoy en día, los gobiernos no protegen nada de lo que antes era sagrado para cada grupo social, por lo que las corporaciones aprovechan para tomar partido y lucrarse de aspectos que parecen preciosos, vulnerables, sagrados o importantes para el interés público.

La publicidad es la herramienta de la cual se valen las corporaciones, para manipular la sociedad y así posicionarse como los grandes titiriteros que manejan los hilos de la comunidad local y mundial. La inversión en publicidad es muy grande, y vemos empresas en las que con siquiatras y psicólogos se crean estrategias para manipular la psiquis de los niños y niñas, formulando sus anuncios y promociones para que puedan acosar a sus padres, y así generar mayor demanda en la venta de sus bienes o servicios. "Se puede manipular a los consumidores en lo que desean y, por tanto, en la compra de sus productos. Es un juego"5 (Lucy Hughes, 2003).

La preocupación de la "marca", domina el mundo actual, la gente puede convertirse en marcas (Martha Stewart) y las marcas pueden construir ciudades (Celebration, Florida), los estudiantes universitarios pueden pagar su educación por ser publicidad en la televisión nacional para una compañía de tarjeta de crédito (Chris y Lucas), hasta una sociedad posee los derechos de la popular canción "Happy Birthday" (una división de AOL-Time-Warner).

\footnotetext{
${ }^{5}$ Lucy Hughes, Vice Presidente de la Corporación “Initiative”, Documental “La Corporación”, Mark Achbar, Joel Bakan, y Jennifer Abbott, 2003.
} 


\section{REVISTA VIRTUAL VIA INVENIENDI ET IUDICANDI \\ "CAMINO DEL HALLAZGO Y DEL JUICIO"}

http://viei.usta.edu.co/ E-MAIL: revistainveniendi@usantotomas.edu.co

Pero la más nefasta de las consecuencias se genera en el hecho de que las personas o grupos de personas que se enfrentan a denunciar las irregularidades en el actuar de las empresas, pagan un alto precio. Jane Akre y Steve Wilson, dos periodistas de investigación de Fox News, realizaron un reportaje sobre RBGH, una polémica hormona sintética, ampliamente utilizada en los Estados Unidos (pero prohibida en Europa y Canadá) para acelerar el metabolismo de las vacas y aumentar su producción de leche, lo que genera que los animales, sufran mastitis, una dolorosa infección de las ubres. Además de la crueldad animal, el peligro que genera para el ser humano consumidor, por el hecho de que deban ser inyectadas con antibióticos, que posteriormente afecta a quien consume la leche y la carne.

Fox exigió que se reescribiera la historia, pero como Akre y Wilson se negaron a cambiarla, fueron despedidos. Los periodistas, posteriormente, demandaron a Fox, demostrando al jurado que la versión de la historia de Fox que hubieran tenido que poner en el aire era falsa, distorsionada o manipulada. Pero Fox apeló, y la sentencia fue anulada por un tecnicismo.

Como se muestra, los tentáculos de las corporaciones atacan miles de campos, pero uno de los que más afecta a sociedades como la colombiana, es el afán de extender su emporio con fines de productividad, por lo que, bajo la idea de progreso para un país tercermundista, grandes corporaciones entran a los países más pobres, con el único fin de lucrarse y aprovechar las leyes laxas, los conflictos armados, la pobreza, entre otros, para así poder actuar sin mayor control y en 


\section{REVISTA VIRTUAL VIA INVENIENDI ET IUDICANDI \\ "CAMINO DEL HALLAZGO Y DEL JUICIO"}

http://viei.usta.edu.co/ E-MAIL: revistainveniendi@usantotomas.edu.co

caso de que algún aspecto no convenga para su desarrollo comercial, lo que simplemente optan por hacer es manipular el poder ya sea militar, político, social o de opinión, debilitar democracias o aprovecharse de las débiles estructuras de poder de muchos países del tercer mundo.

Por todo lo anterior, el primer paso debe ser quitar la venda frente a las poderosas instituciones que controlan nuestros hábitos y necesidades, para ellos sacar lucro de esto, lo cual se ha logrado con propuestas como la participación de la población por medio de votación, en la decisión de la presencia del gigante petrolero Unlocal, en Arcata, California, que fue planteada por medio de la agenda corporativa en el centro de atención pública en una serie de asambleas; en Bolivia, la población luchó y ganó una batalla contra una gran empresa transnacional que pretendía con ayuda del gobierno, privatizar el sistema de agua; en la India casi el 99\% de las patentes de Basmati RiceTek fue anulada, así como sucedió en Europa cuando la Oficina Europea de Patentes (OEP) revocó la patente EP0436257 en el año 2000, pero en Estados Unidos la patente aún sigue vigente. Y en segundo lugar se debe evidenciar ante el mundo los horrores que muchas de estas empresas alrededor del mundo cometen, para conseguir sus fines económicos; denunciar, actuar, para que así se generen mayores controles, que no permitan que las corporaciones actúen libremente, manejando la sociedad. Este sería el único camino, para hacer un llamado a la sociedad y a los miembros 


\section{REVISTA VIRTUAL VIA INVENIENDI ET IUDICANDI}

"CAMINO DEL HALLAZGO Y DEL JUICIO"

http://viei.usta.edu.co/ E-MAIL: revistainveniendi@usantotomas.edu.co

y dirigentes de estas empresas, para que su poder pueda tener repercusión en un cambio social y no sólo en su interés personal.

\section{EMPRESAS MULTINACIONALES ¿TRAFICANTES DE MUERTE EN COLOMBIA?}

Cuando las corporaciones sobrepasan el campo de acción circunscrito a los Estados de los cuales hacen parte, se convierten en empresas multinacionales, donde su poder es cada vez mayor y la capacidad de los Estados es cada vez menor. Así, tales multinacionales han venido extendiendo su alcance a países tercermundistas como Colombia, donde una vez más han demostrado que su interés particular puede primar por encima aún de la vida de las personas. La búsqueda de mayores rendimientos hace que estas empresas esquiven cualquier tipo de presunto obstáculo que se pueda llegar a presentar para la obtención de sus fines.

En Colombia, el egoísmo de las empresas multinacionales lo hemos evidenciado con los casos en los que se ha demostrado que estás no tienen ningún respeto por el llamado "coto vedado" reclamado con insistencia por el profesor Garzón Valdés, ya que estas empresas por su ambición sin límites, se han vinculado con grupos armados al margen de la ley, vínculo que va más allá del financiamiento, convirtiéndose en aliados, aprovechando el accionar de estos grupos en la 


\section{REVISTA VIRTUAL VIA INVENIENDI ET IUDICANDI \\ "CAMINO DEL HALLAZGO Y DEL JUICIO"}

http://viei.usta.edu.co/ E-MAIL: revistainveniendi@usantotomas.edu.co

consecución de sus fines lucrativos financiando sus actividades, que muchas veces tienen que ver con el asesinato de campesinos, trabajadores, indígenas, mujeres, niños y niñas, entre muchos otros crímenes de lesa humanidad.

El primer caso lo encontramos en la empresa Chiquita Brands International, mediante su filial en Colombia BANADEX S.A., la misma empresa, llamada antes, United Fruit Company, que Gabriel García Márquez, escritor Nobel, en su obra Cien años de Soledad, señala como la causante de la llamada "Masacre de las bananeras" el 6 de diciembre de 1928, ya que desplegó una brutal represión contra los trabajadores agrícolas en el Departamento del Magdalena y contra la cual se levantaron sus trabajadores reclamando dignidad. Para sofocar la huelga de los bananeros el Gobierno conservador de Miguel Abadía Méndez lanzó al ejército en contra de los trabajadores, por solicitud de la empresa.

Ochenta años después, Chiquita Brands erige su nombre en la historia colombiana, como una empresa cuyo aporte fue fundamental para que los grupos paramilitares sembraran la barbarie entre miles de personas que fueron asesinadas y masacradas.

Los hechos, paradójicamente, no han salido a la luz, por cuenta de la justicia colombiana, como debería ser, si no que surgido del Departamento de Justicia de Estados Unidos, al iniciarle proceso por una investigación de la Securities and 


\section{REVISTA VIRTUAL VIA INVENIENDI ET IUDICANDI \\ "CAMINO DEL HALLAZGO Y DEL JUICIO"}

http://viei.usta.edu.co/ E-MAIL: revistainveniendi@usantotomas.edu.co

Exchange Commission de ese país, que sindicaba a la empresa de vínculos con los grupos paramilitares de las AUC, incluidos en la lista de grupos terroristas del mundo por el mismo gobierno estadounidense.

De estas investigaciones, se han podido dilucidar varios detalles, que dan cuenta del entramado que se teje tras estos vínculos, desde 1997, tras una reunión entre el gerente de Banadex y Carlos Castaño, máximo jefe de los paramilitares, se creó un vínculo entre la empresa y el grupo, que fue mucho más allá de una simple financiación o de pagarles por seguridad y protección.

Así vemos como, el 7 de noviembre de 2001, Banadex fue la responsable de descargar y almacenar por cuatro días 3.400 fusiles AK-47 y cuatro millones de cartuchos 7.65 , todo camuflado en un embarque de pelotas de caucho a bordo del barco Otterloo. Esto fue documentado en un informe de la OEA que dice que:

"El embarque de armas y municiones fue descargado por una compañía de transporte llamada Banadex S. A. En otro aparte se indica que lo sucedido en Turbo fue un misterio. Investigaciones periodísticas basadas en informes internos de la $\mathrm{DIAN}^{6}$ dan cuenta de cómo Banadex utilizó grúas especiales y montacargas de alta capacidad, que no habrían sido

\footnotetext{
${ }^{6}$ Dirección de Impuestos y Aduanas Nacionales, Unidad Administrativa especial que tiene como función coadyuvar a garantizar la seguridad fiscal del Estado colombiano y la protección del orden público económico nacional, mediante la administración y control al debido cumplimiento de las obligaciones tributarias, aduaneras y cambiarias, y la facilitación de las operaciones de comercio exterior en condiciones de equidad, transparencia y legalidad.
} 


\section{REVISTA VIRTUAL VIA INVENIENDI ET IUDICANDI \\ "CAMINO DEL HALLAZGO Y DEL JUICIO"}

http://viei.usta.edu.co/ E-MAIL: revistainveniendi@usantotomas.edu.co

necesarios si el contenido eran pelotas de caucho. También narra cómo los nueve contenedores en los que venían las armas y la munición estuvieron cuatro días en el lugar, esperando los camiones que los llevaron a Carlos Castaño en el Nudo de Paramillo."7.

En esta operación participaron, se cree, países como Nicaragua, Panamá y la misma Colombia.

Se evidencian negociaciones para obtener operaciones en el puerto que permitiera tener facilidades aduaneras.

"Según la prensa gringa, hay una grabación en la que Escobar [Reinaldo Escobar de la Hoz, quien entre 1997 y 2004 -tiempo en el que se hicieron los pagos a los paras- fue asesor jurídico en unas oportunidades, y representante legal, en otras, de Banadex.] Le explica a un funcionario de Chiquita en Cincinnati que el pago, que en su momento fue por 30.000 dólares, era conveniente porque con el tiempo les ahorraría más de un millón de dólares en gastos aduaneros"8.

Durante el período en que Chiquita Brands financió a las AUC, este grupo cometió miles de asesinatos en la zona bananera, en el Urabá, se generaron miles de desplazamientos, de esta región salieron los aviones con aproximadamente 140

\footnotetext{
7www.verdadabierta.com, Banana "para-republic". Martes, 21 de octubre de 2008. ${ }^{8}$ www.verdadabierta.com, Banana "para-republic". Martes, 21 de octubre de 2008.
} 


\section{REVISTA VIRTUAL VIA INVENIENDI ET IUDICANDI \\ "CAMINO DEL HALLAZGO Y DEL JUICIO"}

http://viei.usta.edu.co/ E-MAIL: revistainveniendi@usantotomas.edu.co

paramilitares que cruzaron el país para cometer la masacre de Mapiripán en Meta, razón por la cual el 15 de septiembre de 2005 la Corte Interamericana de Derechos Humanos condenó al Estado colombiano por colaboración entre miembros del ejército colombiano y los paramilitares en la masacre. Muchas de las víctimas de este grupo armado, en el Urabá antioqueño, fueron trabajadores bananeros a quienes supuestamente la multinacional buscaba defender, pero que en realidad quería eliminar, ya que eran vistos como obstáculos por ser sindicalistas o por simplemente no ofrecer facilidades en su plan productivo.

La multinacional bananera realizó una investigación interna en la que reconstruye la forma y las personas de la compañía que estuvieron involucradas en el pago de extorsiones a la guerrilla y financiamiento de grupos paramilitares durante cerca de 15 años en Colombia.

El mea culpa de la empresa no es sin embargo un mero acto de contrición.

Es también una estrategia jurídica que dentro del sistema judicial estadounidense sirve para evitar demandas de los accionistas. Precisamente la compañía le pide al juez Kenneth Marra del sur de la Florida -el cual lleva 9 de los 10 procesos contra la empresa en Estados Unidos-, que desestime ocho acciones judiciales en las que se solicita que Chiquita sea también responsable ante las familias de personas asesinadas por los grupos criminales que habría financiado ${ }^{9}$.

\footnotetext{
${ }^{9}$ www.verdadabierta.com, El mea culpa de Chiquita Brands. 28 de abril de 2009.
} 


\section{REVISTA VIRTUAL VIA INVENIENDI ET IUDICANDI \\ "CAMINO DEL HALLAZGO Y DEL JUICIO"}

http://viei.usta.edu.co/ E-MAIL: revistainveniendi@usantotomas.edu.co

En octubre de 2008, la empresa llega a un acuerdo con la justicia norteamericana, tras aceptar el haber entregado aportes a las AUC, (calificado como grupo terrorista por ese país desde el 10 de septiembre de 2001) de pagar a título de sanción 25 millones de dólares.

Del acuerdo entre la bananera y el Departamento de Justicia norteamericano, y de la investigación interna realizada por la multinacional, se encuentra también, que la compañía pagó primero a las guerrillas de las FARC y el ELN, entre los años 1989 y 1997.

La justicia estadounidense procesó y multó a varios trabajadores de la multinacional, que estaban vinculados a la empresa entre el primero de enero de 2001 y el 31 diciembre de 2004, en cargos como la Presidencia y algunas vicepresidencias, en la casa matriz de esa compañía, ubicada en Cincinnati, Ohio, quienes confesaron que no sólo sabían que sus directivas en Colombia tenían dudosos tratos con los grupos armados en Colombia sino que orientaron esas "negociaciones".

Los directivos aceptaron que le pagaban a las AUC por medio de la creación de falsas cuentas de contabilidad, al utilizar la figura del incremento salarial a sus empleados en Colombia. 


\section{REVISTA VIRTUAL VIA INVENIENDI ET IUDICANDI \\ "CAMINO DEL HALLAZGO Y DEL JUICIO"}

http://viei.usta.edu.co/ E-MAIL: revistainveniendi@usantotomas.edu.co

Un argumento que esgrimen estas empresas, es que el conflicto armado no deja otra salida, que ceder ante los grupos ilegales, pero no es cierto, Chiquita Brands tenía otras alternativas distintas a aliarse con los delincuentes, lo cual no hizo, y ello tuvo un impacto estremecedor en Urabá y la zona bananera de Santa Marta. Pese a que la bananera aceptó su culpa, en Colombia se inicio un proceso contra Chiquita, Banadex o sus directivos sólo hace tres años, y este caso se estancó sin arrojar ningún resultado concreto. No existen condenas contra esta empresa en Colombia ni por financiación de grupos paramilitares, ni por el soborno pagado para obtener la operación del puerto, ni por el cargamento de armas que ayudaron a entrar. Mientras que en Estados Unidos se ventila judicialmente los más de tres mil casos contra Chiquita Brands, en Colombia, lugar donde cometieron sus crímenes, no existe a la fecha de publicación de este artículo, ninguna condena. Salvatore Mancuso, jefe paramilitar extraditado, hace referencia a los vínculos con estas empresas al ser claro en señalar:

(...) a finales de 1997, el jefe paramilitar Raúl Hasbún, conocido con el alias de 'Pedro Bonito', llegó a un acuerdo con varias bananeras de la región de Urabá, entre las que se encuentran CHIQUITA BRANDS, BANACOL, DEL MONTE, DOLE, PROBAN Y UNIBAN, que pagaban un centavo de dólar por caja exportada a las autodefensas. Este pago se hacía a la Convivir Papagayo, y se destinaba una parte para Carlos 


\section{REVISTA VIRTUAL VIA INVENIENDI ET IUDICANDI \\ "CAMINO DEL HALLAZGO Y DEL JUICIO"}

http://viei.usta.edu.co/ E-MAIL: revistainveniendi@usantotomas.edu.co

Castaño, otra para obras sociales y una tercera parte para el pago de policías corruptos ${ }^{10}$.

Otro jefe paramilitar con el alias H.H (Ever Velosa), señala a Raúl Hasbún, alias Pedro Ponte o Pedro Bonito, quien se desmovilizó el 14 de noviembre de 2004, como el comandante del bloque Bananero en Apartadó. Según su versión, Hasbún "era el encargado de hacer el puente entre la convivir Papagayo y las autodefensas y de coordinar la misión de "prestar seguridad" a la empresa Banadex, filial de la multinacional en Colombia"11.

Hasbún confesó que en su condición de jefe del bloque bananero fue responsable de crímenes contra sindicalistas y agricultores a quienes señalaba de ser guerrilleros, también se resalta que el pago que realizaron las empresas (Chiquita Brands, Del Monte y Dole) no como producto de extorsiones sino como fruto de un acuerdo voluntario entre los paramilitares y los empresarios.

En el expediente, la Fiscalía logró confirmar que Víctor Buitrago Sandoval, ex jefe de seguridad de Banadex S.A., Filial de Chiquita Brands, se reunió con Hasbún en dos ocasiones para pactar los pagos a la convivir Papagayo y descartó la versión de Hasbún quien, en una segunda declaración, trató de exculpar a las bananeras.

10 Ver: Empresario Bananero, un paramilitar sin orden de captura,. en: http://www.prensarural.org/spip/spip.php?article879

${ }^{11}$ Raúl Hasbún o 'Pedro Bonito' se retractó después de señalar que las Convivir en el Urabá Antioqueño fueron financiadas por las empresas bananeras. 


\section{REVISTA VIRTUAL VIA INVENIENDI ET IUDICANDI}

"CAMINO DEL HALLAZGO Y DEL JUICIO"

http://viei.usta.edu.co/ E-MAIL: revistainveniendi@usantotomas.edu.co

En esencia, el Bloque Bananero de las Autodefensas, comandado por Hasbún, se encargaba de la seguridad de la zona agroindustrial en donde recibía contribuciones de sectores relacionados con el banano y de otros grupos.

\section{LA LEY DE RESPONSABILIDAD POR DAÑOS A EXTRANJEROS (ALIEN TORT CLAIMS ACT O ALIEN TORT STATUTE-ATCA),}

De tal forma, al evidenciar las violaciones de empresas multinacionales como ésta, uno de los desafíos que enfrenta el ordenamiento jurídico es el de proporcionar los instrumentos necesarios para garantizar la protección efectiva del individuo frente a los actores no estatales, entre ellos, estas empresas multinacionales. Es así como, los Estados nacionales al no contar con la voluntad política de proveer estos mecanismos de protección, se hace necesario, por parte de las víctimas, acudir a instancias internacionales con el fin de que éstas encuentren una protección efectiva de sus derechos y la reparación integral que reclaman.

Es bien sabido que los Estados pueden ejercer jurisdicción en su propio territorio. Esta jurisdicción incluye el poder de crear normas (jurisdicción legislativa), el poder de interpretar o aplicar normas (jurisdicción contenciosa) y el poder de intervenir para hacer cumplir las normas (jurisdicción coercitiva). Sin embargo, aunque la aplicación de la jurisdicción coercitiva se limita generalmente al territorio nacional, en derecho internacional se admite que, en determinadas circunstancias, un 


\section{REVISTA VIRTUAL VIA INVENIENDI ET IUDICANDI \\ "CAMINO DEL HALLAZGO Y DEL JUICIO"}

http://viei.usta.edu.co/ E-MAIL: revistainveniendi@usantotomas.edu.co

Estado puede legislar respecto de sucesos que se producen fuera de su territorio (jurisdicción extraterritorial) o juzgarlos ${ }^{12}$.

En el campo específico de los Derechos Humanos y los tratados internacionales que los protegen, Estados Unidos se ha caracterizado por ser un país reservado en cuanto a la ratificación de diversos instrumentos de esta naturaleza -como el Estatuto de Roma-, por ejemplo.

Sin embargo, a falta de normatividad interna con relación a violaciones de derechos humanos, diversas decisiones judiciales se han basado en la Ley de responsabilidad por Daños a Extranjeros (Alien Tort Claims Act o Alien Tort Statute-ATCA), ley del año 1789 que establece en el Título 28, Parte IV, Capítulo 85 (Cortes de Distrito-Jurisdicción):

Las cortes de distrito tienen jurisdicción sobre cualquier acción civil que entable un extranjero por un daño únicamente cuando el daño es cometido en violación del derecho de las naciones o un tratado ratificado por Estados Unidos.

En ese contexto, adquiere relevancia el análisis de esta norma, que se ha constituido como un elemento importante para delimitar la responsabilidad de las

\footnotetext{
12 Tomado de Represión nacional de las violaciones del Derecho Internacional Humanitario: Carpeta informativa. Jurisdicción universal sobre crímenes de guerra CICR T.P://www.icrc.org/ Web/spa /sitespa0.nsf/iwpList284/OB29DD529B8E1356C1256DE1005C1744. Acceso 28 de septiembre de 2006.
} 


\section{REVISTA VIRTUAL VIA INVENIENDI ET IUDICANDI \\ "CAMINO DEL HALLAZGO Y DEL JUICIO"}

http://viei.usta.edu.co/ E-MAIL: revistainveniendi@usantotomas.edu.co

empresas multinacionales por implicación en violación de derechos humanos (Martin O., 2008, p. 308). La aplicación del ATCA pone de manifiesto una clara conciencia de que las empresas multinacionales pueden considerarse entre los sujetos susceptibles de violar el derecho internacional y que como tales pueden enfrentarse a procesos para determinar su responsabilidad. En ese sentido, puede decirse que esta jurisprudencia ha contribuido a la consideración de que el derecho internacional impone la obligación a estas empresas de no violar normas de lus Cogens y que dicha violación pueda tener una consecuencia jurídica.

El principal obstáculo procesal de los casos contra empresas multinacionales ha sido la excepción del foro no conveniente o forum non conveniens. De acuerdo con dicha excepción, el tribunal entiende que el foro jurisdiccional en el que se ha interpuesto la demanda no es el apropiado para la decisión del caso a favor del país receptor o del país de origen, donde estuviera registrada la empresa. Para alegar con éxito esta excepción se debe probar que existe un foro alternativo y adecuado y se han de sopesar los intereses públicos y privados presentes en el caso.

En consecuencia, la excepción de forum no conveniens ha sido alegada por prácticamente todas las empresas demandadas en los Estados Unidos por violación de derechos humanos en otros países. Sin embargo, existen mejoras que parecen revertir la afirmación inicial de que la excepción de foro no 


\section{REVISTA VIRTUAL VIA INVENIENDI ET IUDICANDI \\ "CAMINO DEL HALLAZGO Y DEL JUICIO"}

http://viei.usta.edu.co/ E-MAIL: revistainveniendi@usantotomas.edu.co

conveniente era un obstáculo insuperable para todos los casos de litigio trasnacional en materia de derechos humanos. $\mathrm{Y}$ esto es porque los tribunales internacionales están mostrando una mayor propensión por considerar que los foros alternativos son inadecuados para proporcionar un proceso justo y porque están siendo más receptivos a la posición de los demandantes en la valoración de los intereses públicos y privados presentes en el caso.

Uno de los casos más relevantes en cuanto a responsabilidad de empresas multinacionales en los tribunales estadounidenses es el caso UNLOCAL, en 1992 la empresa Estatal Birmana MOGE contrató con la firma FRANCESA TOTAL S.A., la extracción y comercialización de los depósitos de petróleo y gas de la región de Yadana, la empresa estadounidense UNLOCAL compró el $28 \%$ de la participación. Durante el desarrollo de las actividades de extracción, transporte y almacenamientos se produjeron supuestos abusos de derechos humanos por parte del ejército Birmano que incluyeron torturas y otros tratos inhumanos y degradantes como agresiones sexuales, desplazamiento forzado de personas, expropiación de propiedades sin compensación y trabajo forzado. Las denuncias se iniciaron en 1996 en el tribunal del Distrito Central de California, en el 2000, el tribunal concluyo que los demandantes no habían aportado las evidencias necesarias para demostrar que UNLOCAL controlara acciones del ejército Birmano, en cuanto a las demandas de trabajo forzado consideró que los 


\section{REVISTA VIRTUAL VIA INVENIENDI ET IUDICANDI \\ "CAMINO DEL HALLAZGO Y DEL JUICIO"}

http://viei.usta.edu.co/ E-MAIL: revistainveniendi@usantotomas.edu.co

demandantes no podían probar que UNLOCAL habían participado activamente en las practicas de trabajo forzado del ejército.

Sin embargo, en el 2002, el Tribunal Noveno de Circuito continuó con el caso y estableció un vínculo entre las normas de derecho internacional y la responsabilidad de las empresas multinacionales. En el fallo se abordaron cuestiones como: la posible responsabilidad en función del ATCA, la doctrina del Acta de estado para sustanciar la demanda contra UNLOCAL y la falta de jurisdicción material en relación con la ley anticorrupción. Con respecto al primer asunto encuentra que sí puede existir responsabilidad de UNLOCAL en función del ATCA, pues señala que aunque la mayoría de los crímenes requieren acción estatal para ser susceptibles de responsabilidad bajo el ATCA, existe una serie de crímenes a los que la ley de las Naciones atribuye la responsabilidad individual, es decir, que no requieren dicha acción; luego determina el vínculo entre la empresa y los daños cometidos y para ello se apoya en la doctrina de ayudar e incitar utilizada en el derecho penal internacional y en consecuencia establece que UNLOCAL puede ser declarada responsable bajo la ATCA por ayudar e incitar al ejército de Myanmar en la sujeción de los demandantes a trabajo forzado.

Por ayudar e incitar, el Tribunal entiende el conocimiento de que la asistencia práctica o fomento tiene un efecto sustancial en la perpetración del crimen. En él se trataron conceptos como los requisitos de Actus reus: ayudar e incitar y de Mes 


\section{REVISTA VIRTUAL VIA INVENIENDI ET IUDICANDI \\ "CAMINO DEL HALLAZGO Y DEL JUICIO"}

http://viei.usta.edu.co/ E-MAIL: revistainveniendi@usantotomas.edu.co

rea: el conocimiento actual y razonable de sus acciones asistían al ejército en la comisión del crimen.

La anterior decisión estaba llamada a tener un gran impacto en la jurisprudencia posterior y en ella se pusieron mucho las expectativas para el desarrollo de parámetros que permitieran la imputación de responsabilidad. Sin embargo, en diciembre de 2004 llegaron a un acuerdo para finalizar el proceso y los términos del mismo son confidenciales. Por tanto, no podemos saber los compromisos adquiridos ni los motivos del desistimiento de los demandantes.

En el contexto colombiano, uno de los ejemplos es la demanda presentada por la firma de abogados de Willian J. Wichmann y varias organizaciones socias colombianas, ante el distrito Sur de la Florida contra Chiquita Brands International, INC., en 2007, por responsabilidad civil extracontractual internacional, en representación de los familiares de setecientas de las víctimas mortales de las AUC (sindicalistas, trabajadores de Banadex, profesores, estudiantes, niños y otros civiles inocentes) financiadas por Chiquita Brands. En ella se señala que Banadex empezó desde 1997 a hacer pagos ilegales a las AUC; tales pagos se realizaban a través de las "Convivir" que eran presuntas empresas de seguridad asistidas por la policía y militares de Colombia, estas entidades fueron creadas por el gobierno colombiano. Sin embargo, las AUC, no proveían de Seguridad a Chiquita Brands o a Banadex, en vez de ello, las AUC usaban los pagos de las 


\section{REVISTA VIRTUAL VIA INVENIENDI ET IUDICANDI \\ "CAMINO DEL HALLAZGO Y DEL JUICIO"}

http://viei.usta.edu.co/ E-MAIL: revistainveniendi@usantotomas.edu.co

"Convivir" para financiar sus actividades ilegales. Sin embargo, Banadex llamaba a estos pagos "pagos de seguridad".

En la demanda se establece que los pagos efectuados a las AUC fueron revisados y autorizados por los directivos de Chiquita Brands, quienes tenían conocimiento de que estas eran una organización violenta de terroristas, desde que en 2001 se reportó como grupo terrorista en varias publicaciones. Adicionalmente, en septiembre de 2000, una investigación interna de Chiquita Brands reveló los pagos ilegales realizados, los cuales fueron consignados en un memorando que fue discutido y revisado en una reunión en Cincinati, Ohio. Sin embargo, no se tomaron acciones que pararan tales pagos.

La demanda presentada por Wichmann, gira alrededor de cuatro cargos: 1. Por proveer material a organizaciones terroristas que resultaron en muertes, en la que se citan entre otros la violación a la Convención Internacional para la Supresión de la Financiación del Terrorismo, la Ley de las Naciones, la Ley Anti terrorismo, la Ley de lucha contra el terrorismo y pena de muerte efectiva; la Convención Internacional para la Supresión de las Bombas Terroristas. 2. Por ejecuciones extrajudiciales, pues Chiquita Brands causó el asesinato de sus empleados a través de los pagos realizados y en ese sentido condujo a la violación de la Ley de las Naciones, el derecho internacional consuetudinario y los estándares y prácticas de la industria en todo el mundo; 3. Por retención y supervisión 


\section{REVISTA VIRTUAL VIA INVENIENDI ET IUDICANDI \\ "CAMINO DEL HALLAZGO Y DEL JUICIO"}

http://viei.usta.edu.co/ E-MAIL: revistainveniendi@usantotomas.edu.co

negligente, pues Chiquita no tiene un conocimiento actual sobre sus empleados y los actos de sus agentes, además la compañía debía saber que sus agentes continuaban realizando actos inapropiados con la debida revisión, mas cuando se conocen las cifras de asesinatos, secuestros y torturas realizadas por las AUC y en consecuencia los actos de Chiquita Brands no fueron adecuadamente supervisados; y 4. Por contratación negligente, teniendo en cuenta que Chiquita falló en su ejercicio razonable de contratar con las AUC, teniendo conocimiento que las AUC podían violar los derechos de los demandantes y tales contrataciones se constituyen en un resultado directo de dichas violaciones.

Con anterioridad, en ese mismo año se presentó otra demanda contra Chiquita Brands ante el Distrito de Columbia, basada en hechos similares. En ella se indica que la compañía ha contratado a miembros de las autodefensas de Colombia, quienes utilizan una extrema violencia, asesinatos, torturas y detenciones ilegales e individuos por creer que interferían con los negocios de la compañía en Colombia, y quienes tienen el infortunio de residir en zonas paramilitares. Ellos incluyen miembros de la Unión Patriótica, de partidos comunistas, líderes sociales, sindicalistas, defensores de derechos humanos, y todo aquel que denunciara los crímenes cometidos por los paramilitares.

Tales asesinatos se constituyen como ejecuciones extrajudiciales, y no solo violan el ATCA, sino las normas y leyes internacionales en materia de derechos 


\section{REVISTA VIRTUAL VIA INVENIENDI ET IUDICANDI \\ "CAMINO DEL HALLAZGO Y DEL JUICIO"}

http://viei.usta.edu.co/ E-MAIL: revistainveniendi@usantotomas.edu.co

humanos. En algunos casos los demandados hicieron pagos a las Fuerzas Armadas Revolucionarias de Colombia (FARC), el grupo guerrillero que también se ha designado como una organización terrorista por el gobierno de George Bush.

Igualmente, la demanda hace mención a que los demandantes no han podido tener acceso a un sistema legal independiente en Colombia, pues cualquier esfuerzo de los demandantes por obtener justicia y reparación integral sería inútil, porque aquellos que tratan de desafiar la violencia oficial o paramilitar, incluyendo fiscales y activistas de derechos humanos, están en gran riesgo de sufrir graves represalias. En ese sentido, varias organizaciones no gubernamentales de Colombia, han solicitado insistentemente la protección del gobierno colombiano, pese a ello, no se tomaron medidas, y estas quejas fueron en vano debido a la falta de un funcionamiento independiente del sistema judicial colombiano. De hecho el que los grupos paramilitares continúen operando en la mayoría del país y sean financiados por compañías como Chiquita Brands indica el nivel de impunidad que existe en Colombia.

En lo que se refiere a los cargos planteados en la demanda se imputan cargos frente a las ejecuciones extrajudiciales, por infligir la ley de protección a victimas contra la tortura por ejecuciones extrajudiciales, muerte por negligencia, contratación negligente, supervisión negligente, y por infligir angustia emocional 


\section{REVISTA VIRTUAL VIA INVENIENDI ET IUDICANDI \\ "CAMINO DEL HALLAZGO Y DEL JUICIO"}

http://viei.usta.edu.co/ E-MAIL: revistainveniendi@usantotomas.edu.co

intencional. Así, se plantea que parte del "éxito" comercial de Chiquita en Colombia, se debe a que las AUC se apropiaron de las tierras bananeras luego de desplazar y asesinar a miles de campesinos, sindicalistas y miembros de partidos de la oposición, incluyendo decenas de defensores de derechos humanos y otros líderes sociales.

En esas circunstancias, Chiquita Brands solicitó transferencia de la Jurisdicción al distrito de Columbia, alegando foro no conveniente o "Forum non conveniens" con el argumento de que existía una acción pendiente ante dicho órgano jurisdiccional. El Tribunal señala que para determinar la transferencia del caso de un lugar a otro, se deben tener en cuenta factores como: Elección de la jurisdicción por el demandante; La conveniencia de las partes; La conveniencia de los testigos y su disponibilidad a través del proceso obligatorio; La localización de los documentos y las otras fuentes de prueba; La capacidad relativa de las partes de asumir los gastos de cambiar de jurisdicción y la eficiencia de los juicios y gastos para el sistema de justicia.

Inicialmente, indica el tribunal que aunque los demandantes no son residentes del Distrito Sur de la Florida, ni ningún evento se presta para reclamaciones que tengan lugar en ese distrito, los demandados no han argumentado que el Distrito Sur de la Florida es un sitio inadecuado como tal, factor que pesa a favor de los demandantes. Adicionalmente, en cuanto a la conveniencia para los testigos y la 


\section{REVISTA VIRTUAL VIA INVENIENDI ET IUDICANDI}

"CAMINO DEL HALLAZGO Y DEL JUICIO"

http://viei.usta.edu.co/ E-MAIL: revistainveniendi@usantotomas.edu.co

disponibilidad de fuentes de la prueba son inaplicables en este conflicto, pues la sede corporativa de los demandados se encuentra en Ohio, y los dos distritos en cuestión son el distrito sur de la Florida y el Distrito de Columbia, es así como, independientemente de la decisión que se tome en este caso, los testigos de los demandados tendrán que viajar de Ohio a otro lugar para el juicio. Además, no hay pruebas relacionadas con el caso que puedan encontrarse en cualquier lugar. Los demandados alegan que en este caso hay conexiones aparentes al Distrito de Columbia, pues los pagos ilegales realizados por los demandados fueron divulgados por el Departamento de Justicia, con sede en Washington y los motivos criminales fueron consignados en ese Distrito. En cuanto a este punto el tribunal considera esas conexiones insustanciales e irrelevantes para el caso. Pues la prueba de los hechos se hubiese podido demostrar de la misma forma ante ese tribunal, ya que los testigos sólo pueden ser encontrados en Colombia, el lugar específico escogido en los Estados Unidos no tiene mucha relevancia. Por ello esos dos factores no pesan a favor de la transferencia.

Por último, en cuanto a la eficacia de los juicios y gastos para el sistema de justicia los demandados argumentan que sería ineficiente y despilfarrador de los recursos judiciales, permitir que el proceso se siga llevando en ese Distrito porque un caso similar fue presentado primero ante el Distrito de Columbia y porque para ambos casos se requerirá la resolución de algunas cuestiones de hecho y de derecho. Los demandantes responden explicando que los problemas en cada caso son lo 


\section{REVISTA VIRTUAL VIA INVENIENDI ET IUDICANDI \\ "CAMINO DEL HALLAZGO Y DEL JUICIO"}

http://viei.usta.edu.co/ E-MAIL: revistainveniendi@usantotomas.edu.co

suficientemente distintos y por tanto la trasferencia no es justificada. En consecuencia, la moción de traslado al Distrito de Columbia es denegada, y por tanto se declara la jurisdicción personal, y el Distrito Sur de la Florida asume la competencia del caso, proceso que se encuentra en curso actualmente.

Otro caso que analizaremos es el de C.I. Técnica Baltime de Colombia S.A., subsidiaria de la empresa Dole Food CO, multinacional bananera, después de Chiquita Brands fue demandada ante la justicia norteamericana.

Los demandantes son parientes de 51 víctimas de asesinato a manos de miembros del las AUC, las víctimas, según la demanda, eran sindicalistas o pequeños agricultores opuestos a vender sus tierras para que Dole cultivara bananas $^{13}$. La demanda fue presentada en una Corte de Los Ángeles, en California, por el abogado de los demandantes Terry Collingsworth abogado de la firma Conrad and Scherer LLP

El abogado Collingsworth argumenta que la empresa estadounidense realizó pagos regulares a las AUC que totalizaron unos 10 millones de dólares entre 1997 al 2007, así como hizo otros pagos menores a esas milicias incluso tiempo atrás como en 1994, a cambio las AUC se encargaron de "mantener alejados a los sindicatos de las plantaciones de bananos de Dole, a través de asesinar a líderes

\footnotetext{
${ }^{13}$ www.verdadabierta.com. "Dole también financió paramilitares en Colombia, según demanda", 29 de abril de 2009.
} 


\section{REVISTA VIRTUAL VIA INVENIENDI ET IUDICANDI \\ "CAMINO DEL HALLAZGO Y DEL JUICIO"}

http://viei.usta.edu.co/ E-MAIL: revistainveniendi@usantotomas.edu.co

sindicales y usar tácticas de terror para desestimular el ingreso de trabajadores a los sindicatos"14.

Aseguró que entre los cargos presentados en el pleito se resalta que las AUC prestó servicios violentos para DOLE incluyendo el desplazamiento de pequeños granjeros de su tierra para permitir que DOLE plantara banano; y en el proceso de asesinar a "miles" de personas inocentes, incluyendo los parientes de los 73 demandantes; asesinando a dirigentes sindicales y usando tácticas de terror para desalentar a los trabajadores sindicalizados a la hora de negociar convenciones colectivas con DOLE.

Los administradores de DOLE sabían de eso cuando daban un nombre a las AUC por problemas de seguridad o preocupación, lo que significaba que las AUC ejecutarían a esas personas sin investigar o ninguna otra averiguación, según la demanda.

La demanda se apoya en versiones de paramilitares, como el ex comandante del frente William Rivas, José Gregorio Mangones Lugo, alias 'Carlos Tijeras' y varios de sus subcomandantes donde afirman que "cuando DOLE quería que algo se hiciera, el gerente de la plantación llamaba directamente a uno de los subcomandantes y le daba un nombre o una descripción y las AUC iba y se hacía cargo".

\footnotetext{
${ }^{14}$ www.verdadabierta.com. "Dole también financió paramilitares en Colombia, según demanda", 29 de abril de 2009.
} 


\section{REVISTA VIRTUAL VIA INVENIENDI ET IUDICANDI \\ "CAMINO DEL HALLAZGO Y DEL JUICIO"}

http://viei.usta.edu.co/ E-MAIL: revistainveniendi@usantotomas.edu.co

Alias 'Carlos Tijeras', manifiesta en las versiones libres que realizaron en los procesos iniciados a la luz de la Ley de Justicia y Paz, que:

Todas las bananeras, menos Chiquita, que existen hoy en día y las que existieron, me pagaban a mí 70 mil pesos por hectárea anual", dijo el ex jefe 'para', sumándose así a las afirmaciones entregadas por otros ex comandantes ya extraditados como Salvatore Mancuso, 'Jorge 40' y ' $\mathrm{HH}^{\text {'15. }}$.

Alias Mangones, figura entre otros cuatro ex comandantes de las AUC quienes han dicho que todas las empresas bananeras foráneas que operaron en Colombia, incluyendo Dole, Del Monte y Chiquita Brands, hicieron pagos.

También han confesado haber ordenado varios miles de asesinatos, principalmente en la región de la costa caribeña colombiana, y dirigidos específicamente a sindicalistas y supuestos simpatizantes de las guerrillas.

El impacto de muerte por el apoyo a estas empresas no se dio solamente en Urabá, sino también en Magdalena, donde los sectores económicos dedicados a la producción y comercialización del banano, café y ganado fueron los principales financiadores. En la demanda se sostiene que DOLE realizó pagos por más de 10 millones de dólares al Bloque Norte de las Autodefensas liderado por Rodrigo

\footnotetext{
${ }^{15}$ El 13 de mayo de 2008 se extraditan a 14 jefes exparamilitares que se habían acogido a la Ley de Justicia y Paz, por delito de narcotráfico.
} 


\section{REVISTA VIRTUAL VIA INVENIENDI ET IUDICANDI \\ "CAMINO DEL HALLAZGO Y DEL JUICIO"}

http://viei.usta.edu.co/ E-MAIL: revistainveniendi@usantotomas.edu.co

Tovar Pupo, alias "Jorge 40," con operaciones basadas en Cesar, Magdalena y La Guajira.

El sector bananero es el que más evidencia las oscuras alianzas entre paramilitares y multinacionales, pues no suficiente con el ejemplo de estas dos multinacionales demandadas, encontramos el caso de la multinacional Del Monte, la cual al igual que las anteriores, es señalada por los mismos altos jefes paramilitares de financiar grupos armados ilegales a cambio de beneficios particulares, a costa de la vida de cientos de personas, que a su modo de ver, entorpecían el desarrollo productivo de su organización económica.

Esta alianza entre paramilitares y empresas bananeras se debió a que el grupo armado ilegal entró con una intención política y militar, comandada por los hermanos Castaño Gil, dirigentes de las AUC, de arrebatarle el poder a la guerrilla sobre algunos sectores sociales, entre ellos, los sindicatos y las fincas bananeras.

"Sí realizamos acciones militares que beneficiaran la producción bananera, impidiendo que se realizaran paros laborales y presionando a los empleados de las bananeras para que trabajaran bajo amenazas" ${ }^{16}$.

Salvatore Mancuso, el más alto jefe paramilitar extraditado, hace referencia a los vínculos con estas empresas al decir:

\footnotetext{
${ }^{16}$ dijo el ex jefe paramilitar H.H. el 15 de abril de 2008, cuando compareció ante los magistrados de la Corte Suprema de Justicia que investigan las relaciones de algunas multinacionales con las autodefensas en Urabá.
} 


\section{REVISTA VIRTUAL VIA INVENIENDI ET IUDICANDI \\ "CAMINO DEL HALLAZGO Y DEL JUICIO"}

http://viei.usta.edu.co/ E-MAIL: revistainveniendi@usantotomas.edu.co

"a finales de 1997, el jefe paramilitar Raúl Hasbún, conocido con el alias de 'Pedro Bonito', llegó a un acuerdo con varias bananeras de la región de Urabá, entre las que se encuentran Chiquita Brands, Banacol, Del monte, Dole, Proban y Uniban, que pagaban un centavo de dólar por caja exportada a las autodefensas. Este pago se hacía a la Convivir Papagayo, y se destinaba una parte para Carlos Castaño, otra para obras sociales y una tercera parte para el pago de policías corruptos"17.

De igual forma, en el famoso programa noticiero estadounidense "60 Minutes" del 11 de mayo de 2008, "[e]l exjefe paramilitar Salvatore Mancuso aseguró, que la multinacional Chiquita Brands aceptó pagarle a los grupos paramilitares por su seguridad sin que hubiesen existido amenazas y se ofreció a revelar todos los vínculos de las multinacionales con los paramilitares en Colombia. [...]:

'No no es cierto que hayan sido presionados', dice Mancuso. 'Ellos pagaban impuestos porque eran como un estado en la zona, y porque se les proporcionaba la protección que les permitía seguir haciendo inversiones y un beneficio económico', explicó Mancuso. Además el ex jefe paramilitar aseguró que Chiquita Brands no habría sido la única empresa que accedió a pagar a los paramilitares por su seguridad. 'Todas las empresas en la región

\footnotetext{
17 Ver: Empresario Bananero, un paramilitar sin orden de captura. Consultar en: http://www.prensarural.org/spip/spip.php?article879
} 


\section{REVISTA VIRTUAL VIA INVENIENDI ET IUDICANDI \\ "CAMINO DEL HALLAZGO Y DEL JUICIO"}

http://viei.usta.edu.co/ E-MAIL: revistainveniendi@usantotomas.edu.co

bananera pagaron. Por ejemplo, Dole y Del Monte, que, creo, son compañías de EE.UU.', dijo a la cadena norteamericana" ${ }^{\prime 18}$.

El diario El Espectador el 5 de septiembre de 2009 reveló que para la fiscalía, Chiquita Brands, realizó maniobras financieras para continuar en el país después de 2004, incluso las empresas que heredaron sus operaciones siguieron haciendo aportes a las AUC hasta 2007.

En tal informe se señala que Chiquita Brands nunca se fue del país. Desde los tiempos de la masacre de las bananeras (1928), con su antiguo nombre United Fruit Company, hasta la barbarie paramilitar que arrasó a sangre y fuego el Urabá, la cuestionada compañía norteamericana, que financió durante años a las autodefensas, sigue teniendo presencia en Colombia. En el año 2004, una vez descubierto su patrocinio a este grupo ilegal, supuestamente cesaron sus actividades comerciales, al tiempo que enfrentó un sonado proceso en Estados Unidos donde fue condenada a pagar US\$25 millones por haber financiado a las AUC.

No obstante, según la fiscalía sus operaciones fueron asumidas por dos firmas: Invesmar S.A. y Olinsa. La primera tiene como líder en Colombia a Banacol S.A., la cual al parecer siguió haciendo aportes ilegales a las AUC entre 2004 y 2007,

\footnotetext{
${ }^{18}$ José Alvear Restrepo, Colectivo de Abogados.

http://www.colectivodeabogados.org/article.php3?id_article=1456\#nb3. Ingreso 12 de febrero de 2009.
} 


\section{REVISTA VIRTUAL VIA INVENIENDI ET IUDICANDI \\ "CAMINO DEL HALLAZGO Y DEL JUICIO"}

http://viei.usta.edu.co/ E-MAIL: revistainveniendi@usantotomas.edu.co

más exactamente a la convivir Papagayo y otras que eran controladas por Raúl Emilio Hasbún, desmovilizado a la luz de la Ley de Justicia y Paz, lo cual fue reconocido por este excomandante en sus versiones libres y adicionalmente los análisis contables arrojaron la destinación de dineros a las convivir:

Un experimentado analista contable de la Fiscalía, tras analizar los movimientos financieros del grupo empresarial de Banacol, estableció que "por concepto de banano" se destinaba un dinero importante a las Convivir, pagos que se habrían hecho voluntariamente tal y como ocurrió con Chiquita Brands. Así lo detalló en un informe contable conocido por El Espectador, fechado el 22 de julio de $2008^{19}$.

La segunda empresa Olinsa, fue creada en 2005 por una ex empleada de confianza de Chiquita Brands, Gloria Andrea Cuervo, la empresa inició con un capital de 20 millones y curiosamente pronto recibió una inyección económica de Chiquita Brands por 1152 millones por concepto de préstamo a una tasa muy inferior a la del promedio del mercado. Por otro lado, la Fiscalía descubrió que entre 2005 y 2008 Chiquita Brands le aportó US\$5 millones y se constituyó como su principal cliente.

Entre el 11 y 12 de noviembre del 2008 una comisión del CTI de la Fiscalía realizó una inspección judicial a la sede de Olinsa en la capital antioqueña, donde se

\footnotetext{
${ }^{19}$ http://www.elespectador.com/impreso/judicial/articuloimpreso159808 chiquita-sigue-colombia
} 


\section{REVISTA VIRTUAL VIA INVENIENDI ET IUDICANDI \\ "CAMINO DEL HALLAZGO Y DEL JUICIO"}

http://viei.usta.edu.co/ E-MAIL: revistainveniendi@usantotomas.edu.co

encontraron registros contables que estrecharon la conexión entre la firma y Chiquita Brands, Lo que confirma que Chiquita Brands nunca se fue de Colombia. Sin embargo, según este informe existen complicaciones en el proceso, pues no hay certeza de quiénes son los verdaderos dueños de Invesmar S.A., porque la firma está domiciliada en un paraíso fiscal. Pero no ha sido el único inconveniente de la Fiscalía en este proceso, debido a un acuerdo de confidencialidad con el Departamento de Justicia de los Estados Unidos, no se tiene certeza de las identidades de los directivos de Chiquita Brands en ese país, y de la abundante información contable que resolvería muchos enigmas del apoyo que durante una década les prestaron a las autodefensas.

Esta avanzada investigación, que por más de un año adelantó un fiscal delegado ante la Corte, entró en una etapa definitiva y hace pocos días fue reasignada a un fiscal de Medellín, que se apresta a definir la situación jurídica de los implicados de las firmas cuestionadas, que paradójicamente se encuentran en el vecino municipio de Envigado, y que todo apunta son enlaces en Colombia de Chiquita Brands, una empresa que ha financiado presidentes y senadores en Estados Unidos y que tiene una cuenta pendiente con las víctimas de la Auc en Urabá ${ }^{20}$.

\footnotetext{
${ }^{20} \mathrm{http}: / /$ www.elespectador.com/impreso/judicial/articuloimpreso159808 chiquita-sigue-colombia
} 


\section{REVISTA VIRTUAL VIA INVENIENDI ET IUDICANDI \\ "CAMINO DEL HALLAZGO Y DEL JUICIO"}

http://viei.usta.edu.co/ E-MAIL: revistainveniendi@usantotomas.edu.co

Otra de las empresas demandadas ante la justicia estadounidense por cometer graves violaciones a los derechos humanos en Colombia es la multinacional Drummond INC, que es la mayor explotadora de carbón en Colombia, registrada en Alabama, cuya principal ocupación es la explotación y exportación de carbón. Entre otros lugares, la compañía Drummond, posee y opera la mayor mina de carbón a cielo abierto del mundo, una línea férrea y un puerto, todo ello en Colombia.

Esta empresa, muestra una realidad nada diferente a los casos anteriores, ya que muchos sindicalistas de Sintramienergia han denunciado que la multinacional del carbón estaba seriamente comprometida en el crimen de varios sindicalistas (Valmore Locarno, Víctor Hugo Orcasista, Gustavo Soler y Cándido Méndez).

Rafael García, exjefe de informática del DAS, denunció en mayo de 2006 que Augusto Jiménez, Presidente de la Drummond en Colombia había dado a Rodrigo Tovar Pupo, alias Jorge 40, la suma de 200.000 euros con el objeto de que procedieran contra los referidos sindicalistas.

Pero en Colombia, las investigaciones fueron archivadas, incluso el mismo señor presidente de la república Álvaro Uribe Vélez, varias veces hizo defensa pública de la empresa señalando que estaba siendo víctima de una encerrona. Ante la imposibilidad de acceder a la justicia en el ordenamiento nacional, los familiares 


\section{REVISTA VIRTUAL VIA INVENIENDI ET IUDICANDI \\ "CAMINO DEL HALLAZGO Y DEL JUICIO"}

http://viei.usta.edu.co/ E-MAIL: revistainveniendi@usantotomas.edu.co

de las víctimas y el sindicato decidieron llevar a esta empresa, de igual forma que los ejemplos anteriormente citados, ante la justicia estadounidense, donde fue demandada por la utilización de los "servicios" de grupos paramilitares colombianos para proteger sus instalaciones mineras y vías férreas en Colombia. Se denunciaron vínculos con los paramilitares, se les permitía entrar libremente a las instalaciones mineras, se les proveía de combustible y finalmente se reafirma que los directivos de la filial de esta empresa en Colombia, con pleno conocimiento ayudaron e instigaron a las fuerzas paramilitares que asesinaron a Lacarno, Orcasita, Soler y Méndez, dándoles apoyo financiero, provisiones, acceso y otra ayuda substancial que contribuyeron a que las fuerzas paramilitares pudieran asesinar a los mencionados líderes sindicales ${ }^{21}$.

En este caso, el Tribunal de Alabama en USA, desestimo las contundentes evidencias contra Drummond y falló a favor de la empresa acusada de la muerte de los líderes sindicales: Cándido Méndez, Valmore Locarno Rodríguez y Víctor Hugo Orcasita Amaya, presidente y vicepresidente de Sintramienergética y por los cuales la Fiscalía General de la Nación profirió resolución de acusación en contra de Rodrigo Tovar Pupo, alias 'Jorge 40', y Óscar José Ospino Pacheco, alias "Tolemaida", el día 6 de enero de 2009.

\footnotetext{
${ }^{21}$ Observatorio social de empresas transnacionales megaproyectos y DH. http://www.observatoriocolombia.info/?q=node/192. Ingreso 12 de febrero de 2009.
} 


\section{REVISTA VIRTUAL VIA INVENIENDI ET IUDICANDI \\ "CAMINO DEL HALLAZGO Y DEL JUICIO"}

http://viei.usta.edu.co/ E-MAIL: revistainveniendi@usantotomas.edu.co

En la demanda interpuesta por los familiares de Cándido Méndez, asesinado el 19 de febrero de 2001, se relata como Drummond y las AUC, abiertamente asociadas conspiraron para asesinar a los miembros del sindicato, un acto que condujo a la muerte de Méndez, miembro de la Unión de Trabajadores de la Minería y la Industria de la Energía de Colombia ("Sintramienergética"). Se señala allí que una parte sustancial de los hechos sucedió en Colombia.

Además de mantener las instalaciones para el uso de las AUC, los miembros acusados coordinaron las actividades de éstos bajo la supervisión de Alfredo Araujo, gerente de relaciones comunitarias de Drummond Ltda. Así, el sindicato fue capaz de iniciar negociaciones con los acusados en un intento por resolver las cuestiones relacionadas con el trabajo, tales como la protección de los empleados de los paramilitares. No obstante, luego de estas negociaciones las partes demandadas comenzaron a realizar amenazas a la Unión y sus miembros.

La demanda señala el testimonio de uno de sus familiares presente durante su asesinato:

"El 18 de febrero de 2001, Cándido Méndez, se dio cuenta que en su camino al trabajo había un camión sospechoso estacionado junto al autobús de la Empresa. Dicho camión se parecía a los utilizados por los paramilitares. En su camino a casa fue seguido por el que parecía ser el mismo camión. Al día 


\section{REVISTA VIRTUAL VIA INVENIENDI ET IUDICANDI \\ "CAMINO DEL HALLAZGO Y DEL JUICIO"}

http://viei.usta.edu.co/ E-MAIL: revistainveniendi@usantotomas.edu.co

siguiente Méndez fue sacado de su casa e inmediatamente fue recibido por aproximadamente treinta hombres y fue asesinado delante de su familia. Algunos de esos hombres vestían uniformes paramilitares, algunos uniformes de policía, y los otros estaban vestidos de civil".

Ante la demanda mencionada Drummond interpone una moción para que el Tribunal la desestime basada en la falta de jurisdicción personal, lugar inadecuado y un servicio insuficiente del proceso, igualmente, argumenta que los demandantes no han podido invocar una violación de la ley de las naciones y por tanto ese tribunal no tiene competencia en el tema. Según los demandados, la desestimación se justificaba porque el caso sucedió como parte de un conflicto de Colombia, donde existen los recursos jurídicos disponibles para los demandantes. Los demandados alegaron que los demandantes podrían participar como parte civil en los procedimientos penales respectivos o, alternativamente, presentar una demanda contra los responsables o contra cualquier tercero privado cómplice, dentro de la jurisdicción ordinaria de Colombia en virtud de una acción civil. No obstante, los demandantes señalan que la jurisdicción colombiana sería adecuada si las partes no se vieran privadas de los recursos y garantías necesarias o si su vida y seguridad no corriera riesgo.

Efectivamente, el Tribunal de Alabama, desestima la pretensión de los demandantes considerando que las acusaciones de los demandantes son de 


\section{REVISTA VIRTUAL VIA INVENIENDI ET IUDICANDI \\ "CAMINO DEL HALLAZGO Y DEL JUICIO"}

http://viei.usta.edu.co/ E-MAIL: revistainveniendi@usantotomas.edu.co

terrorismo en general y no son lo suficientemente específicas para configurar una violación a la ley de las naciones. De la misma forma, argumenta que los hechos alegados no entran dentro de cualquiera de los actos prohibidos, enumerados específicamente y establecidos en el Convenio de Financiación, y que los demandantes no alegan que el daño ocasionado se produjo durante un conflicto armado. Por las anteriores razones la demanda es desestimada con sede en falta de jurisdicción personal.

Para cerrar el estudio de casos de las aparentes relaciones de las multinacionales con los grupos armados ilegales en Colombia, encontramos a una de las más importantes empresas en el mundo, Coca Cola.

Desde principios de la década de los noventa, Coca Cola, viene siendo señalada por el Sindicato Nacional de la Industria de la Alimentación (SINALTRAINAL) como responsable del asesinato de por lo menos 14 miembros de su agremiación, entre ellos 7 miembros del sindicato de Coca-Cola y, de igual modo, propiciar el desplazamiento forzado de varias decenas de sus miembros, lo que incluye, por supuesto, el exilio de un par de trabajadores sindicalizados. Denuncian el allanamiento de sedes sindicales y también las reiteradas amenazas contra familiares y miembros del sindicato. Varios de los sindicalistas asesinados fueron ultimados mientras se estaban negociando pliegos de peticiones y diversas voces 


\section{REVISTA VIRTUAL VIA INVENIENDI ET IUDICANDI \\ "CAMINO DEL HALLAZGO Y DEL JUICIO"}

http://viei.usta.edu.co/ E-MAIL: revistainveniendi@usantotomas.edu.co

no han dejado de señalar como responsables de dichos crímenes al paramilitarismo en complicidad con los organismos del Estado ${ }^{22}$.

La importancia de este caso, la da el hecho que la denuncia traspasó las fronteras y ha convocado la solidaridad de trabajadores de distintos países, incluida la del sindicato metalúrgico estadounidense United Steelworkers of America (Uswa), que junto a otras agremiaciones sindicales procedieron en el año 2001 a instaurar una demanda ante un Juez Federal contra la compañía y, además, contra dos de sus embotelladoras por considerarlas responsables de crímenes y persecución contra los sindicalistas colombianos.

El 31 de marzo de 2003 un juez federal aceptó el trámite en Florida de la demanda del sindicato United Steelworkers of America contra dos embotelladoras de Coca Cola en Colombia Bebidas y Alimentos, y Panamerican Beverages, por permitir e incitar a los grupos paramilitares al «asesinato, tortura y persecución de los trabajadores que intentaban sindicarse».

La denuncia apunta a que Bebidas y Alimentos conspiró con grupos paramilitares para matar al líder sindical Isidro Gil en la nave de la empresa y así eliminar la fuerza sindical Sinaltrainal en la planta embotelladora ubicada en Carepa, Urabá

\footnotetext{
${ }^{22}$ Un pormenorizado informe sobre la Coca-Cola en Colombia y otros países puede verse en: CIEPAC. Centro de Investigaciones Económicas y Políticas de Acción Comunitaria de San Cristóbal de las Casas, México. Versión electrónica. http://www.columnasur.org/CIEPAC/menú.htm
} 


\section{REVISTA VIRTUAL VIA INVENIENDI ET IUDICANDI \\ "CAMINO DEL HALLAZGO Y DEL JUICIO"}

http://viei.usta.edu.co/ E-MAIL: revistainveniendi@usantotomas.edu.co

antioqueño, Colombia, que opera «bajo control y autoridad» de Coca Cola, y a la que, según el sindicato, Ariosto Mosquera, el encargado de la embotelladora, invitó a los paramilitares a entrar para «exterminar el sindicato». Horas después, los paramilitares incendiaron la oficina de Sinaltrainal en Carepa. Dos días más tarde, los paramilitares volvieron a la factoría y obligaron a los trabajadores a renunciar a su militancia en el sindicato bajo amenaza de muerte. La compañía asegura en su web que «Coca-Cola Co. y sus plantas embotelladoras locales han dado prioridad a la seguridad de sus trabajadores y representantes sindicales» y que Mosquera había dejado su trabajo cinco días antes.

Los acusados conjuntamente pidieron que se desestimara la denuncia por falta de competencia en el tema. Los demandantes alegaron que la conducta ilícita presuntamente cometida por los paramilitares se imputa a los acusados a través de la conspiración, la agencia y la complicidad. Dentro de ese proceso, el tribunal del distrito rechazó la demanda contra Coca- Cola, por falta de competencia en el tema porque, según el Tribunal, la parte actora no demostró que los acusados violaron la ley de las naciones, entendida como una violación a las normas de derecho internacional consuetudinario.

El Juez desestimó la denuncia en marzo del 2003 contra Coca-Cola, pero el boicot y la solidaridad ante este proceder presuntamente ilegal por parte de esta multinacional no ha dejado de sentirse, hasta el punto que varios campus 


\section{REVISTA VIRTUAL VIA INVENIENDI ET IUDICANDI \\ "CAMINO DEL HALLAZGO Y DEL JUICIO"}

http://viei.usta.edu.co/ E-MAIL: revistainveniendi@usantotomas.edu.co

universitarios en los EEUU y en Europa han hecho recientemente un llamado para que los productos que expende la Coca-Cola a su interior sean retirados hasta tanto no se clarifique cuál es y ha sido su responsabilidad ante los hechos que se le imputan ${ }^{23}$.

Desde finales del año 2005 y principio del 2006, varias campañas contra la multinacional Coca-Cola se desplegaron en varios campus universitarios. Así, la Universidad de Míchigan ${ }^{24}$ y la de Nueva York retiraron los productos Coca-Cola y otro tanto han hecho varios centros educativos en Inglaterra, Irlanda e Italia, entre otros. El lema que los ha hermanado es: Porque amo la vida no tomo Coca-Cola. Esta campaña se suma a otras que en otros momentos fueron impulsadas en el año 2003 por distintos actores. Esta situación para los directivos de la multinacional les ha resultado incómoda y como nunca antes han tenido que salir a dar las explicaciones de rigor frente a las punzantes denuncias que se les hace. En este sentido Edgar E. Potter, director de Relaciones Laborales Globales de Coca-Cola dijo en una carta al abogado Terry Collingsworth, director ejecutivo del Fondo Internacional para los Derechos Laborales, organización con sede en Washington y quien representa legalmente a los sindicalistas que:

\footnotetext{
${ }^{23}$ El Tiempo. 5 de enero de 2006. "10 universidades de EU y Europa vetaron el consumo de Coca-Cola por nexos con los paras". Bogotá D.C.

${ }^{24}$ Sobre lo asumido por la Universidad de Míchigan puede verse la nota publicada por: Latin América Solidarity Centre. Versión digital http//:www.lasc.ie/new/coke-new8.html.
} 


\section{REVISTA VIRTUAL VIA INVENIENDI ET IUDICANDI \\ "CAMINO DEL HALLAZGO Y DEL JUICIO"}

http://viei.usta.edu.co/ E-MAIL: revistainveniendi@usantotomas.edu.co

The Coca-Cola Company y sus embotelladoras han entrevistado a testigos de los asuntos en cuestión y confían en la suficiencia de esas investigaciones. Estas no encontraron evidencia de que los administradores de las plantas embotelladoras de Coca-Cola en Colombia conspiraran con paramilitares para amenazar o intimidar sindicalistas, ni evidencia de que administradores de plantas embotelladoras de Coca-Cola tengan algún papel en la muerte [de sindicalista $]^{25}$.

Lo anterior demuestra cómo una estrategia para llamar la atención de las directivas de esta empresa, y de la comunidad internacional en general, es el generar campañas de concientización que permitan percibir la realidad que se esconde tras los intereses de las multinacionales, y como en muchos casos, con tal de evitar la influencia de los sindicatos en sus empresas, y en aras de aumentar el lucro, como lo señalan las demandas mencionadas, se alían con grupos armados ilegales o como el caso de Chiquita Brands, este apoyo se realiza para aprovechar los beneficios aduaneros que conllevaba aliarse con los paramilitares, a sabiendas de la sangre, muerte y barbarie que su apoyo conllevaría.

\footnotetext{
${ }^{25}$ El Tiempo. 5 de enero de 2006. "10 universidades de EU y Europa vetaron el consumo de Coca-cola por nexos con los paras". Bogotá D.C.
} 


\section{REVISTA VIRTUAL VIA INVENIENDI ET IUDICANDI}

"CAMINO DEL HALLAZGO Y DEL JUICIO"

http://viei.usta.edu.co/ E-MAIL: revistainveniendi@usantotomas.edu.co

\section{CONCLUSIONES}

La reflexión final a la que se quiere llegar, después de todo el estudio de las instituciones predominantes de la sociedad, llamadas corporaciones, materializadas en empresas y extendidas mundialmente bajo la denominación de multinacionales, es sí se debe seguir cerrando los ojos ante el desbordado poder que a éstas, la misma sociedad les ha otorgado, lo cual ha permitido graves violaciones a los derechos humanos, como las cometidas en nuestro país.

Sobre los asuntos y crímenes denunciados por las organizaciones de la sociedad civil, fruto de la presunta alianza entre las multinacionales señaladas en este artículo y los grupos armados ilegales, no existen fallos condenatorios de la justicia colombiana. Las víctimas de estos grupos, siguen sin justicia, reparación y sin verdad, y prefieren permanecer en el anonimato, ya que temen las represalias de los socios de esta alianza, por un lado, los miembros de grupos al margen de la ley que no se desmovilizaron o se han rearmado a la luz del fallido proceso de Justicia y Paz, por el otro, de lo que conlleve el enfrentarse con un emporio tan poderoso como el que representan las multinacionales.

La memoria es un antídoto contra la impunidad, desde el año 1928 cuando sucedió la masacre de las bananeras, señalada por los sobrevivientes de estos hechos como una acción conjunta de la United Fruit Company y el Gobierno 


\section{REVISTA VIRTUAL VIA INVENIENDI ET IUDICANDI \\ "CAMINO DEL HALLAZGO Y DEL JUICIO"}

http://viei.usta.edu.co/ E-MAIL: revistainveniendi@usantotomas.edu.co

Nacional de la época. Hoy esta empresa se llama Chiquita Brands y ochenta años después sigue siendo cuestionada por su apoyo a grupos al margen de la ley que han utilizado estos recursos para cometer los más graves crímenes contra la población civil.

Pensemos por un momento, de ser ciertas estas acusaciones, ¿Que hubiera ocurrido en Colombia, si las multinacionales, Chiquita, Dole, Del Monte, Drummond y la misma Coca Cola, hubieran elegido no apoyar, financiar y pactar alianzas con los grupos armados ilegales?, tal vez, se hubieran evitado miles de muertes, desplazamientos, amenazas, desapariciones, exilios, masacres, entre otros muchos crímenes más.

Debemos dar a conocer ampliamente herramientas jurídicas como la Ley de responsabilidad por Daños a Extranjeros (Alien Tort Claims Act o Alien Tort Statute-ATCA), ley del año 1789 que establece en el Título 28, Parte IV, Capítulo 85: "Las cortes de distrito tienen jurisdicción sobre cualquier acción civil que entable un extranjero por un daño únicamente cuando el daño es cometido en violación del derecho de las naciones o un tratado ratificado por Estados Unidos". Esta herramienta es una más de las que debemos utilizar para lograr la reparación integral a las víctimas de graves violaciones a los derechos humanos cometidas en Colombia, en las cuales presuntamente y confesadas por los más altos jefes 


\section{REVISTA VIRTUAL VIA INVENIENDI ET IUDICANDI \\ "CAMINO DEL HALLAZGO Y DEL JUICIO"}

http://viei.usta.edu.co/ E-MAIL: revistainveniendi@usantotomas.edu.co

paramilitares, algunas empresas multinacionales tienen un alto grado de responsabilidad.

\section{REFERENCIAS}

Achbar, M. Bakan, J. \& Abbott, J. (2003). La Corporación. Instituciones Psicópatas. Big Picture media.

Bourdieu, P. (1998, marzo). La esencia del Neoliberalismo. Le Monde diplomatique. Paris.

CIRC. (2006). Represión nacional de las violaciones del Derecho Internacional Humanitario. Carpeta informativa. Jurisdicción universal sobre crímenes de guerra. http://www.icrc.org/Web/spa/sitespa0.nsf/iwpList284/0B29DD529B8E1356C1256D E1005C1744. Acceso 28 de septiembre de 2006.

Comisión Económica para América Latina - CEPAL, Organización de Naciones Unidas. (2002).Globalización y desarrollo.

Chiva, V. (activista y líder ecologista). En Documental La Corporación.

Chomsky,N. (2003). En Documental "La Corporación".

De Sousa Santos, B. (1998). La globalización del derecho. Los nuevos caminos de la regulación y la emancipación. Universidad Nacional de Colombia - Facultad de Derecho, Ciencias Políticas y Sociales, Instituto Latinoamericano de Servicios Legales Alternativos (ILSA).

El Tiempo. 5 de enero de 2006. "10 universidades de EE.UU. y Europa vetaron el consumo de Coca-Cola por nexos con los paras". Bogotá D.C. 


\section{REVISTA VIRTUAL VIA INVENIENDI ET IUDICANDI \\ "CAMINO DEL HALLAZGO Y DEL JUICIO"}

http://viei.usta.edu.co/ E-MAIL: revistainveniendi@usantotomas.edu.co

Financial Times (1999, enero). (Suplemento especial).

Garzón Valdés, E. (1992). II Seminario Eduardo García Máynez sobre Teoría y Filosofía del Derecho, organizado por el Instituto Tecnológico Autónomo de México (ITAM) y la Escuela Libre de Derecho. Ciudad de México 15, 16 y 17 de octubre.

Gibara, S. (2003). En Documental La Corporación.

Gnoss Man, R. (2003). (Derecho y Democracia, POCLAD). En documental La Corporación.

Hare, R. (mayor experto mundial en psicópatas). En Documental La Corporación.

Lasn, K. (1999). Sabotaje cultural: Manual de uso. Editorial El Viejo Topo.

Mateus, J.R., (2002). Brasset, D.W. La globalización: sus efectos y bondades. Economía y Desarrollo $1(1)$.

Ortega O., M. (2008). Empresas Multinacionales y Derechos Humanos en el Derecho Internacional. J.M Bosch. (Editor).

Observatorio social de empresas transnacionales megaproyectos y $\mathrm{DH}$. http://www.observatoriocolombia.info/?q=node/192. Ingreso 12 de febrero de 2009. Robinson, W.I. (2000, agosto). La globalización capitalista y la transnacionalización del Estado. En Revista Web Mensual de Economía, Sociedad y Cultura. 2000. http://www.globalizacion.org/articulos/GutierrezBodCultura.htm Tedesco, J.C. (2000). Educación y sociedad del conocimiento y de la información. En Revista Colombiana de la Educación. 


\section{REVISTA VIRTUAL VIA INVENIENDI ET IUDICANDI \\ "CAMINO DEL HALLAZGO Y DEL JUICIO"}

http://viei.usta.edu.co/ E-MAIL: revistainveniendi@usantotomas.edu.co

Zinn, H. (2006?). Historiador, autor: La otra historia de Estados Unidos. En Documental La Corporación.

http://www.prensarural.org/spip/spip.php?article879

http://www.prensarural.org/spip/spip.php?article879

www.verdadabierta.com, Banana "para-republic". Martes, 21 de octubre de 2008.

www.verdadabierta.com. El mea culpa de Chiquita Brands. 28 de abril de 2009.

www.verdadabierta.com. Dole también financió paramilitares en Colombia, según

demanda. Miércoles, 29 de abril de 2009.

http://www.colectivodeabogados.org/article.php3?id_article=1456\#nb3. Ingreso 12 de febrero de 2009.

http://www.elespectador.com/impreso/judicial/articuloimpreso159808chiquitasigue-colombia. 